\title{
Decomposing Factor Momentum
}

\author{
Hanlin Yang*广
}

July 11, 2020

\begin{abstract}
Factor momentum returns do not stem from momentum in factor returns. To study the source of returns, this paper decomposes the factor momentum portfolio into a factor timing portfolio and a static portfolio, where the former dynamically collects the return due to serial correlations of factor returns and the latter passively collects factor premiums. Evidence from 210 stock return factors reveals that the static portfolio robustly accounts for a dominant fraction of the factor momentum return and outperforms in risk-adjusted returns, whereas factor return predictability is empirically too weak to produce timing benefits. The static portfolio survives the post-publication decline of factor performance but the factor momentum portfolio does not.
\end{abstract}

JEL Classification: G11, G12, G17

Keywords: Factor momentum, time-series predictability, factor timing portfolio, buy-and-hold portfolio

\footnotetext{
*Department of Banking and Finance, University of Zurich, Switzerland, email: hanlin.yang@bf.uzh.ch.

${ }^{\dagger}$ I thank Robert Anderson, Nicholas Gunther, Paul Schneider and the seminar participants at UC Berkeley and SFI Research Days for their helpful comments and suggestions. This research project was conducted while I was a visiting doctoral researcher at Haas School of Business, UC Berkeley. I am grateful for the financial support by the Swiss National Science Foundation Doc.Mobility Fellowship.
} 


\section{Introduction}

The momentum effect in financial markets describes the phenomenon that past winner (loser) assets tend to outperform (underperform) in the future. The momentum strategy, which buys (sells) past winner (loser) assets, has been shown to earn robust profits in many asset classes consistently over time. ${ }^{1}$ Recently, momentum in the cross-section of long-short anomaly portfolio returns, or stock return factors, has received researchers' attention (Avramov et al., 2017; Zaremba and Shemer, 2018). It is not simply a profitable investment strategy but also reveals broader asset pricing implications. For instance, Arnott et al. (2019) and Ehsani and Linnainmaa (2019) argue through the lens of a factor structure that the momentum in industry portfolios and individual stocks originates from factor momentum. Because factor momentum times factors directly without trading noises in individual stock returns, it subsumes stock momentum and industry momentum and produces significant excess returns.

The prime goal of this paper is to explore the source of factor momentum returns. In literature, factor momentum is perceived to earn profits because prior returns predict future returns. This factor timing benefit correlates with the level of predictability. If the magnitude of the average return is large in the cross-section, factor momentum may also profit from the mean-return channel (Conrad and Kaul, 1998). That is, the long (short) leg could often be factors with positive (negative) average returns; such a static factor position can be still profitable in the absence of time-series predictability.

The focus of this study will be the time-series momentum strategy constructed in the spirit of Moskowitz et al. (2012). This strategy goes long (short) in factors with positive (negative) prior returns and with a unit total position equally assigned to each factor in the

\footnotetext{
${ }^{1}$ The momentum effect has been studied by Jegadeesh (1990) and Jegadeesh and Titman (1993) in the cross-section of stocks, Moskowitz and Grinblatt (1999) in industry stock portfolios, Jostova et al. (2013) in corporate bonds, Okunev and White (2003) and Menkhoff et al. (2012) in foreign currencies, Chan et al. (2000), Moskowitz et al. (2012) and Asness et al. (2013) for wide asset classes in international markets. Geczy and Samonov (2016) extend evidence of stock momentum back to 1800s.
} 
investment set. The factor position is rebalanced at a monthly frequency. This form of factor momentum is slightly different from other factor momentum strategies studied by literature and is motivated by the property of rotational invariance, namely, the property that the corresponding stock position does not vary with how one defines the long and short legs of each factor. The empirical study is therefore free from defining factors.

In forming factor momentum strategies, I consider a total of 210 stock return factors, which are either publicly available or constructed based on CRSP and Compustat data. This factor zoo covers most factors examined by recent large-scale replication studies. The factor return is the monthly return of zero-cost long-short portfolios double-sorted by size and each characteristic. The sample period extends from July 1965 to December 2018 with a maximum of 642 monthly returns for each factor. The motivation to consider a large universe of factors is that with a large cross-section of factor returns one can study the cross-sectional implication of crucial factor return characteristics such as the level of predictability and return mean on factor momentum returns. Second, considering a large universe of factors minimizes factor selection bias in portfolio formation.

Conventional studies of the momentum return such as Lo and MacKinlay (1990), Lewellen (2002) and Ehsani and Linnainmaa (2019) examine the source of returns by estimating a hypothetical decomposition in sample. However, two problems arise. First, statistically significant predictability does not necessarily imply that the actual portfolio gain is also large. Second, the profitability of factor momentum, as will be shown in portfolio formation, may also hinge on the out-of-sample predictability. Empirical evidence, however, suggests that the out-of-sample predictability is overall weak. For instance, only the seasonality factor (Heston and Sadka, 2008) is significantly predictable out of sample at the 1-\% level according to the one-sided Clark and West (2007) statistic. The factor momentum return is therefore unlikely to stem from time-series predictability.

To study the source of factor momentum returns, I decompose the factor momentum 
strategy into two factor strategies which directly measure the respective portfolio gain from each channel. The first strategy is a one-sided, dynamic factor timing portfolio and trades the factor if the short-term return deviates from the prevailing return mean, and holds a zero factor position if they move in the same direction. It therefore isolates the factor timing benefts from factor premiums. The second strategy holds a quasi-static factor position: It consistently goes long (short) in factors with high (low) prevailing mean return and is henceforth called (quasi-) buy-and-hold portfolio. This factor position is quasi-static in the sense that it rebalances the factor position only if the sign of the prevailing mean changes, which occurs rarely in history. It passively collects factor premiums and is argued by Huang et al. (2019) to be the major driver of time-series momentum returns in international futures markets.

The factor momentum strategy and its two components are formed based on the prior one-year return skipping the most recent month to keep consistency with the Jegadeesh and Titman (1993) stock momentum factor. In analyzing the factor momentum return, the stock momentum factor is used as a benchmark as it is an implicit way of trading factor momentum but does not involve active factor timing (Ehsani and Linnainmaa, 2019). The corresponding spanning regression alpha measures the excess return that can be gained from managing factors directly relative to stock momentum. The factor portfolios are formed not on the entire factor zoo but on each quintile group of factors sequentially sorted by the level of predictability or return mean. Specifically, each month, the level of predictability is estimated as the slope coefficient from regressing monthly returns on the prior one-year return skipping one month, and the size of the return mean is estimated by the prevailing average return in absolute value. Factor portfolios are maximally exposed to the most predictable or profitable factors through sequential factor sorts. The out-of-sample predictability, rather than in-sample predictability, transmits into portfolio gains. This construction also guarantees that portfolio performance is not subject to selection bias, which can be equivalently understood as forward-looking bias in portfolio formation. 
When factors are sequentially sorted by the level of predictability, the timing strategy and momentum strategy of factors in the top quintile earn an economically small average return or insignificant regression alpha relative to the stock momentum factor. This empirical finding suggests that even timing the most predictable factors does not lead to significant benefits. The portfolio performance is therefore consistent with above statistical evidence of weak out-of-sample predictability. The return of the buy-and-hold portfolio, however, is statistically significant for all quintile groups. The return of the buy-and-hold portfolio and factor momentum portfolio on the top quintile group of factors becomes more significant when factors are sequentially sorted by absolute return mean. Moreover, for both sorts, the buy-and-hold portfolio accounts for a dominant fraction of the total return of factor momentum. Investors who hold the buy-and-hold portfolio harvest factor momentum profits without trading noises in factor momentum.

Publicly available factors such as those studied by Hou et al. (2015), Stambaugh and Yuan (2017) and Daniel et al. (2019) are often included as the most profitable factors in above sorts. These factors are perceived as the common risk factors of the cross-section and are therefore a sparse representation of the whole universe of stocks or factors. I therefore also consider public US and global factors summarized in Table A.1 for portfolio formation and document exactly the same finding. Empirically, the factor timing portfolio and buy-and-hold portfolio have an annual return of $-1.06 \%$ and $4.47 \%$ and Sharpe ratio of -0.21 and 1.23 . Combining both components, the factor momentum portfolio only earns an annual return of $3.41 \%$ and Sharpe ratio of 0.71 .

The factor timing benefit is also weak among factors that are the most predictable in the entire sample history. Specifically, factors are sorted into quintile groups by the fullsample estimates of the level of predictability or return mean. This is equivalent to assuming that investors observe the entire history of factor returns and form portfolios on the most predictable or profitable factors only. Through this factor sort the factor timing benefit 
correlates with the level of in-sample predictability. However, the return of the factor timing portfolio formed on the top quintile group remains insignificant, whereas the buy-and-hold portfolio continues to outperform by producing larger and more significant returns. These results show that the in-sample predictability also corresponds to weak timing benefits.

Simulation studies show that the buy-and-hold portfolio formed on the top quintile of factors sequentially sorted by absolute return mean also outperforms those formed on fixed subsets of factors. Each time, 42 factors (one-fifth of the total population) are randomly selected to form above factor portfolios. The return of the sorted buy-and-hold portfolio is hard to reach by all simulated portfolios. For all simulations, the buy-and-hold portfolio contributes a dominant fraction of the total factor momentum return, which in other words implies that the predictability being too weak to produce factor timing benefits is a universal phenomenon among all possible combinations of factors.

There is evidence that stock momentum stems from factor momentum (Ehsani and Linnainmaa, 2019). Spanning tests show that the buy-and-hold portfolio captures the level of factor momentum (and consequently stock momentum) returns, whereas the factor timing portfolio captures the time-variation in factor momentum (and consequently stock momentum). Combining both components, factor momentum explains both the level and variation of the stock momentum factor with overall the greatest explanatory power compared to any single factor. For instance, some factors such as the monthly updated value (Asness and Frazzini, 2013), price (Blume and Husic, 1973) and 52-week high (George and Hwang, 2004) only explain the time-variation, whereas other factors such as the post-earning announcement drift (Bernard and Thomas, 1990), global quality (Asness et al., 2019) and global beta arbitrage (Frazzini and Pedersen, 2014) only explain the level of stock momentum returns.

Above findings are robust to portfolio formation. In the first exercise of robustness checks, I vary the number of included factors for portfolio formation. Specifically, each month, top $n$ factors ranked by the return spread are used to construct above factor portfolios, with $n$ 
varying from 1 to 210. Second, I consider formation and holding periods up to one year. When the holding period is longer than one month, the holding-period returns overlap. This paper uses the Jegadeesh and Titman (1993) approach to construct nonoverlapping monthly portfolio returns. Third, because the stock momentum factor skips one month in formation, I instead consider the momentum of Fama-French 17-industry portfolios formed based on the prior one-month return as the benchmark for factor momentum with one-month formation and holding periods. For any formation, the buy-and-hold portfolio continues to be the bestperforming strategies and produces a larger fraction of the total factor momentum return.

If the factor momentum return stems from a static factor position, one may wonder whether the publication of factors results in a decay in its performance as the return of each single factor may be exploited by arbitrageurs or even simply a statistical artifact (McLean and Pontiff, 2016). To explore this effect, each month, only top 21 or 42 published factors ranked by return mean are used for portfolio formation. The portfolios of published factors are further compared with those formed on all factors. One can see a decay in the empirical performance of the buy-and-hold portfolio, but it still produces the greatest Sharpe ratio and the most significant excess return relative to stock momentum and industry momentum among all strategies. It also outperforms the majority of single factors post-publication. On the contrary, the momentum portfolio of published factors can no longer outperform the stock momentum factor.

This paper contributes to the emerging factor momentum literature. Avramov et al. (2017) first document evidence of momentum in the cross-section of anomaly portfolio returns. Zaremba and Shemer (2018) study factor momentum in global markets. Arnott et al. (2019) and Ehsani and Linnainmaa (2019) provide evidence that industry momentum and stock momentum stem from factor momentum. Gupta and Kelly (2019) and Yang (2019) develop profitable volatility-scaled factor momentum strategies. This paper finds that the factor momentum return mostly stems from a static position in profitable factors, contrasting 
with conventional understanding that it is a consequence of predictable variations in factor returns.

The empirical methodology builds on a decomposition of the factor momentum strategy. This decomposition is motivated by Huang et al. (2019), who document similar findings for futures markets. The decomposition allows one to study the respective portfolio gain from time-series predictability and factor premiums, whereas the literature studies the source of momentum returns through a hypothetical decomposition coupled with in-sample estimates; see, for instance, Lo and MacKinlay (1990), Conrad and Kaul (1998), Lewellen (2002), Moskowitz et al. (2012) and Ehsani and Linnainmaa (2019). In particular, Conrad and Kaul (1998) argue that the stock momentum return can be explained by the cross-sectional variation of stock returns, which is similar to this paper's finding for stock return factors. Ehsani and Linnainmaa (2019) find that time-series predictability is the major source of factor momentum returns based on in-sample estimates. Lastly, this paper employs factor sorts to enrich empirical evidence on the source of factor momentum returns.

The rest of this paper proceeds as follows. Section 2 describes the constructed factor dataset. Section 3 presents main empirical results and Section 4 studies portfolio performance post-publication. Section 5 concludes.

\section{Data}

This paper considers a total of 210 cross-sectional stock return predictors to enrich empirical evidence. These predictors are examined by recent large-scale replication studies such as Harvey et al. (2016), McLean and Pontiff (2016), Freyberger et al. (2017), Green et al. (2017), Linnainmaa and Roberts (2018), Gupta and Kelly (2019) and Hou et al. (2020) and are summarized in Table A.1. The returns of the corresponding long-short anomaly portfolios are simply called stock return factors in this paper though in literature factors generally 
refer to those that may also price the cross-section. All factors are constructed based on CRSP and Compustat data. Financial firms with a one-digit SIC code of 6 are excluded for portfolio formation. ${ }^{2}$ Moreover, only common equities with a share code of 11 and 12 , and listed on NYSE, Amex and Nasdaq with an exchange code of 1, 2 and 3 are considered. When portfolios are formed, missing pre-delisting returns are replaced by contemporaneous CRSP value-weighted market returns. Following Shumway (1997), missing delisting returns are replaced by $-30 \%$ for NYSE and Amex stocks and $-50 \%$ for Nasdaq stocks.

Stocks are $2 \times 3$ independently sorted by size and each characteristic following Fama and French (1993) according to NYSE breakpoints. Using NYSE breakpoints for both size and firm characteristics reasonably account for micro-caps that are influential on anomalies but constitute only a small market share (Fama and French, 2008; Hou et al., 2020). For factor portfolios based on accounting variables from Compustat, only firms with more than one-year history in Compustat and a positive book value are included. Definition of the book value follows Davis et al. (2000). Similar to the construction of the Fama and French (1993) value factor, stocks are sorted into small and big groups according to the median NYSE size. Stocks are further independently sorted into three groups based on the breakpoints for the bottom $30 \%$ (low), middle $40 \%$ (medium) and top 30\% (high) of the ranked value of each characteristic for NYSE stocks. ${ }^{3}$ Six value-weighted portfolios are then obtained from the intersection of two size and three characteristic groups. The return of each factor is obtained by going long (short) in portfolios formed on the two top (bottom) groups and equally weighted across size groups to account for the size effect on stock return anomalies

$$
\text { factor } \left.=\frac{1}{2}(\text { small high }+ \text { big high })-\frac{1}{2} \text { (small low }+ \text { big low }\right) .
$$

\footnotetext{
${ }^{2}$ I follow Asness et al. (2000) and use Fama-French 48-industry classification for four industry-adjusted portfolios studied by them. Other industry-adjusted portfolios use SIC codes for classification.

${ }^{3}$ There are three binary predictors: net stock issuance (NSI, Fama and French, 2008) and share issurance (SI1, SI5, Pontiff and Woodgate, 2008). The corresponding portfolios go long (short) in stocks with positive (negative) characteristics.
} 
Noteworthy, some factors in literature are defined as the return of the corresponding lowminus-high portfolios, but it turns out that switching the long and short legs results in the same stock position due to the property of rotational invariance to be discussed in portfolio formation. As the characteristic may negatively predict future stock returns, this construction does not guarantee that each factor earns a positive average return in history.

Because stock and industry momentum will be the benchmark strategies in analyzing the empirical performance of factor momentum, they are excluded from the factor zoo to avoid inducing a mechanical correlation. Among all factors, 19 US factors and 8 global factors for developed markets excluding US are publicly available. ${ }^{4}$ 17, 23, 9 and 134 factors are based on CRSP daily, CRSP monthly, Compustat quarterly and Compustat annual data. Factors constructed merely from CRSP data are rebalanced on a monthly basis, and factors based on Compustat annual data are rebalanced in the end of June and held for one year. Factors based on Compustat quarterly data such as the revenue surprise (RS, Jegadeesh and Livnat, 2006) are rebalanced at a monthly frequency. The sample period extends from July 1965 to December 2018 with a maximum of 642 monthly returns for each factor.

Lastly, for sanity checks, I construct the value factor based on the book-to-market ratio and find that it has a correlation coefficient of 0.98 with the Fama-French construction. The return mean and Sharpe ratio of other factors are compared with the estimates provided by Feng et al. (2019) and Hou et al. (2020) and found to be highly consistent. It is therefore convincing that above portfolio formation does not induce bias that makes the results significantly deviate from literature.

\footnotetext{
${ }^{4}$ Specifically, US and global Fama and French (2015) factors, long-term reversal (LREV) and three valuation factors (EP, CP, DY) are available from the Kenneth French Data Library. Investment to asset (IA) and return on equity (ROE) studied by Hou et al. (2015) are available from Macro Finance Society and downloaded from WRDS. Three US and global AQR factors (BAB, HMLD, QMJ) are also included. Other publicly available factors include liquidity (LIQ, Pástor and Stambaugh, 2012), mispricing factor related to management (MGMT, Stambaugh and Yuan, 2017), intermediary capital ratio (ICR, He et al., 2017), postearning announcement drift (PEAD) and financing factor (FIN) from Daniel et al. (2019). The mispricing factor related to performance studied by Stambaugh and Yuan (2017) is constructed from stock momentum and therefore excluded.
} 


\section{Empirical Methodology}

\subsection{Factor Momentum}

I construct the time-series factor momentum strategy in the spirit of Moskowitz et al. (2012). Specifically, let $F_{i, t}$ be the month- $t$ return of the $i$-th factor, $\mathcal{I}_{t}$ the set of factors and $\left|\mathcal{I}_{t}\right|$ the number of factors included for portfolio formation in month $t$. The factor momentum strategy goes long (short) in factors that earn a positive (negative) prior return with a unit total position equally assigned to all included factors. The factor momentum portfolio (FM) is rebalanced at a monthly frequency with the month- $(t+1)$ return given by

$$
r_{t+1}^{\mathrm{FM}}=\frac{1}{\left|\mathcal{I}_{t}\right|} \sum_{i \in \mathcal{I}_{t}} \operatorname{sign}\left(F_{i,-t}\right) F_{i, t+1}
$$

$F_{i,-t}$ is the average monthly return within the prior one year skipping the most recent month to keep consistency with the Jegadeesh and Titman (1993) construction of stock momentum,

which factor momentum is benchmarked against in analyzing its empirical performance. The stock momentum factor skips one month because stock returns tend to reverse at the onemonth horizon.

In the study of the stock return cross-section, Goyal and Jegadeesh (2017) argue that the excess time-series momentum return relative to cross-sectional momentum stems from a net long stock position. Because each factor is a zero-cost long-short portfolio, the time-series factor momentum strategy maintains a zero net stock position and is therefore not subject to the Goyal and Jegadeesh (2017) critique. Factor momentum can be therefore perceived as a consequence of pure factor bets.

Above form of factor momentum is different from other factor momentum strategies studied by Arnott et al. (2019), Ehsani and Linnainmaa (2019) and Gupta and Kelly (2019) and is motivated by the fact that the corresponding stock position does not vary with how one defines 
the long and short legs of each factor (Yang, 2019). To see this property, note that the timing benefit of each included factor can be written equivalently as

$$
\operatorname{sign}\left(F_{i,-t}\right) F_{i, t+1}=\operatorname{sign}\left(-F_{i,-t}\right)\left(-F_{i, t+1}\right)
$$

This identity implies that if one rotates the long and short legs of each factor, she meanwhile receives an opposite trading signal. The study of factor momentum is therefore free from defining factors.

Before presenting the empirical results, I demonstrate the source of factor momentum profits through a hypothetical example. Consider a time-series factor momentum strategy that opens a factor position of

$$
w_{t}^{\mathrm{FM}}=\frac{1}{N} \cdot F_{-t}
$$

where $F_{-t}$ is the column vector of prior factor returns and $N$ is the number of included factors. The expected return, following Moskowitz et al. (2012), can be decomposed similarly as

$$
\mathbb{E}\left[F_{t+1}^{\top} w_{t}^{\mathrm{FM}}\right]=\frac{1}{N} \cdot \operatorname{Trace}\left(\Omega_{F}\right)+\frac{1}{N} \cdot \mu_{F}^{\top} \mu_{F},
$$

where $\Omega_{F}=\mathbb{E}\left[\left(F_{-t}-\mu_{F}\right)\left(F_{t+1}-\mu_{F}\right)^{\top}\right]$ is the cross-covariance matrix and $\mu_{F}$ is the column vector of average factor returns. This strategy goes long (short) in factors with a positive (negative) prior return and with the position size proportional to the magnitude of the prior return. The first component is the average autocovariance and captures the factor timing benefit. This component is argued by Arnott et al. (2019) and Ehsani and Linnainmaa (2019) to be the major driver of factor momentum profits. However, if the magnitude of the average return is large in the cross-section, factor momentum may also profit from the mean-return channel (Conrad and Kaul, 1998), which is reflected in the second component in equation 
(5). That is, the long (short) leg could often be factors with a positive (negative) average

return; such a static position is still profitable in the absence of time-series predictability as it passively collects factor premiums over time.

\subsection{Summary Statistics}

The previous decomposition implies that the level of autocovariance and return mean are determinants of the factor momentum return. This section presents relevant summary statistics. The autocovariance of factor returns is captured by the regression coefficient $\beta$ of the predictive regression

$$
F_{i, t}=\alpha+F_{i,-t} \beta+\epsilon_{i, t}
$$

Panel A of Figure 1 displays the bivariate scatter plot of the ordinary least squares (OLS) estimate of $\beta$ and the average return in absolute value. It can be seen that both estimates exhibit substantial dispersion. The most persistent factors can be attributed to accounting anomalies such as the operating profitability-to-asset ratio (OPA, Ball et al., 2015) and operating leverage (OL, Novy-Marx, 2011) or bet on market frictions such as the beta arbitrage (BAB, Frazzini and Pedersen, 2014), delayed responses to market movements (Delay, Hou and Moskowitz, 2005) and seasonality (SE25, Heston and Sadka, 2008). Among all factors, ICR earns the largest return spread (11.8\%). Other profitable factors include BAB, GBAB and FIN. However, most factors have an annual return below 4\%. Lastly, there is a weak, positive relation between the level of predictability and return mean: A 1\% increase in return mean correlates with an 8 basis point increase in the estimate of $\beta$.

The magnitude of the regression coefficients and their unreported robust $t$-statistics suggest that the returns of many factors are predictable in sample. However, two problems arise. First, statistically significant predictability does not necessarily imply that the actual portfolio 

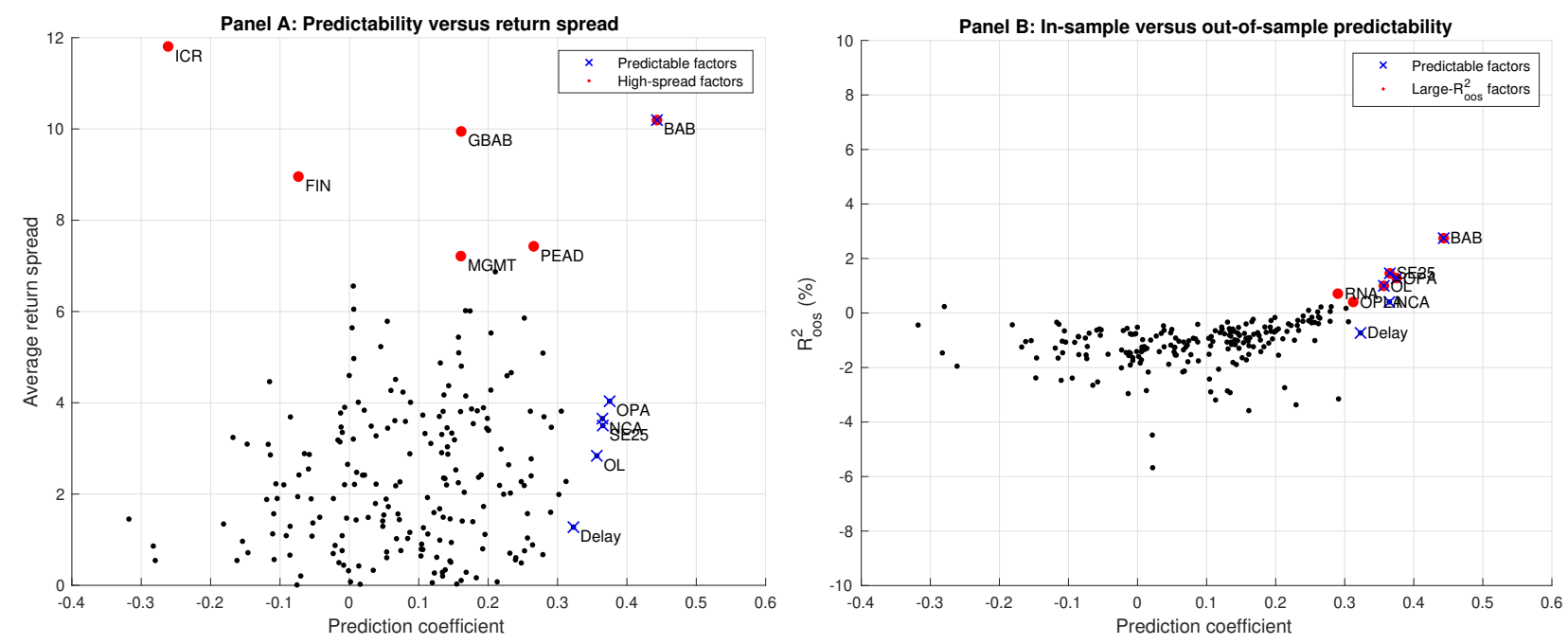

Figure 1: Bivariate scatter plot of factor return characteristics. This figure displays the bivariate scatter plot of (1) the OLS estimate of $\beta$ in equation (6) versus the absolute average return spread, and (2) the OLS estimate of $\beta$ versus the percentage $R_{\text {oos }}^{2}$-value. The return spread is annualized and reported in percentage.

gain is also large. Second, the profitability of factor momentum, as will be shown in portfolio formation, may also hinge on the out-of-sample predictability. I follow Campbell and Thompson (2008) and Welch and Goyal (2008) and calculate the $R_{\text {oos-value, which measures to what }}^{2}$ extent the predictor outperforms the prevailing mean in out-of-sample prediction. In calculating the $R_{\mathrm{oos}}^{2}$-value, three-year monthly data are used to form the initial estimate. Panel B of Figure 1 compares the full-sample estimate of $\beta$ with the corresponding $R_{\text {oos-value. There }}^{2}$ is a strong positive relation, but only 14 factors deliver a positive $R_{\text {oos }}^{2}$-value. Among all, only the return of SE25 is significantly predictable out of sample at the 1\%-level according to the one-sided Clark-West statistic (Clark and West, 2007). The out-of-sample predictability is therefore overall statistically insignificant.

\subsection{Decomposing Factor Momentum}

Given above concerns, I directly explore the actual portfolio gain from each channel. Specifically, the factor momentum strategy is decomposed into two factor strategies that collect the 
return from factor timing and the mean-return channel, respectively. The portfolio return follows

$$
\begin{aligned}
r_{t+1}^{\mathrm{FT}} & =\frac{1}{\left|\mathcal{I}_{t}\right|} \sum_{i \in \mathcal{I}_{t}}\left(\operatorname{sign}\left(F_{i,-t}\right)-\operatorname{sign}\left(\bar{F}_{i, t}\right)\right) F_{i, t+1}, \\
r_{t+1}^{\mathrm{BH}} & =\frac{1}{\left|\mathcal{I}_{t}\right|} \sum_{i \in \mathcal{I}_{t}} \operatorname{sign}\left(\bar{F}_{i, t}\right) F_{i, t+1},
\end{aligned}
$$

where $\bar{F}_{i, t}$ is the prevailing mean of the $i$-th factor estimated from all data available up to month $t$. The first strategy is a dynamic, one-sided factor timing portfolio and trades the factor if the short-term return deviates from the the prevailing mean, and holds a zero factor position if they move in the same direction. It therefore isolates the factor timing benefit from factor premiums. The second strategy holds a quasi-static factor position in the sense that it is rebalanced only if the sign of the return mean changes, which, however, occurs rarely in history. It passively collects factor premiums and is argued by Huang et al. (2019) to be the major driver of time-series momentum returns in international futures markets. That the quasi-buy-and-hold strategy captures the return from the mean-return channel is underpinned by a hypothetical portfolio with static position

$$
w_{t}^{\mathrm{BH}}=\frac{1}{N} \cdot \mu_{F}
$$

This strategy goes long (short) in factors with a positive (negative) average return and with the expected return exclusively coming from the second component of decomposition (5)

$$
\mathbb{E}\left[F_{t+1}^{\top} w_{t}^{\mathrm{BH}}\right]=\frac{1}{N} \cdot \mu_{F}^{\top} \mu_{F}
$$




\subsection{Empirical Performance}

This paper views factor selection as part of portfolio formation to understand the relation between factor return characteristics and factor momentum returns. In previous studies of factor strategies, portfolio formation is restricted to fixed sets of factors and therefore subject to selection bias. For instance, if one focuses on the most predictable factors only, she implicitly relies on the full-sample estimate of the prediction coefficient. This paper considers sequential factor sorts based on a large universe of factors, which minimizes factor selection bias and mimicks investors' real-time portfolio choice.

Specifically, each month, factors are ranked by the sequential estimates of the prediction coefficient in equation (6) or absolute return mean, which are denoted by $\beta_{\text {seq }}$ and $\left|\mu_{\text {seq }}\right|$, respectively. For factor sorts, a minimum of three-year data are needed to form the initial estimates of the prediction coefficient. In reported results, $\beta_{\text {seq }}$ is estimated using all data available up to the corresponding month, but the conclusion does not change when it is estimated within rolling time windows.

Factors are sorted into quintile groups by above characteristics, where the top (bottom) group consists of factors with the highest (lowest) level of predictability or return mean. Factors in each group are then used to form the factor momentum portfolio, factor timing portfolio and buy-and-hold portfolio. After factors are sorted into quintile groups, the return of each quintile factor portfolio is realized in the next month. The out-of-sample predictability therefore transmits into portfolio returns through sequential factor sorts.

To study their empirical performance, I benchmark them against the cross-sectional stock momentum factor as it is an implicit way of trading factor momentum but does not involve active factor timing (Ehsani and Linnainmaa, 2019). I use the stock momentum factor (MOM) data available from the Kenneth French Data Library as a proxy for the stock momentum return. The stock momentum factor is the monthly return of the long-short portfolio double- 
sorted by size and prior one-year return skipping one month.

For each factor portfolio, I run the spanning regression

$$
r_{t}^{\mathrm{FM}(\mathrm{FT}, \mathrm{BH})}=\alpha+r_{t}^{\mathrm{MOM}} \beta+\epsilon_{t}
$$

where the regression alpha measures the excess return that can be earned by actively managing factors relative to stock momentum. I also look at the adjusted $R^{2}$-value, which measures the fraction of portfolio return variation that is also reflected in stock momentum. The reverse regression is also considered, and its regression estimates, while omitted, can be interpreted in a highly consistent way.

Panel A of Table 1 indicates that for the factor timing strategies both the average return and excess return relative to stock momentum increase in the level of predictability. However, none of them produces positive excess returns. The portfolio return for the top quintile is positive but small in magnitude $(0.54 \%)$. Therefore, the factor timing benefit is weak even among the most predictable factors. This finding is consistent with statistical evidence of weak out-of-sample predictability. The return difference between extreme quintile groups is economically small and suggests that an incremental level of predictability correlates with only a marginal increase in the factor timing benefit.

Panel B indicates that the excess return of the buy-and-hold portfolio in all quintile groups has a robust $t$-statistic uniformly above 2 . Because these quintile portfolios are sorted by $\beta_{\text {seq }}$, the level of predictability appears to be inconsequential to the buy-and-hold portfolio return. Moreover, a comparison between Panels $\mathrm{A}$ and $\mathrm{B}$ demonstrates that the factor momentum return mostly stems from the buy-and-hold portfolio and is therefore not a consequence of factor timing. Lastly, Panel $\mathrm{C}$ shows that even factor momentum of the most predictable factors can hardly outperform stock momentum as the excess return is insignificant with a robust $t$-statistic of 1.56 , contrasting with recent literature favoring predictability as the source 
Table 1: Factor Portfolio Returns Relative to Stock Momentum

\begin{tabular}{|c|c|c|c|c|c|c|c|c|}
\hline \multirow[b]{2}{*}{ Group } & \multicolumn{4}{|c|}{ Panel A: FT sorted by $\beta_{\text {seq }}$} & \multicolumn{4}{|c|}{ Panel D: FT sorted by $\left|\mu_{\text {seq }}\right|$} \\
\hline & Mean & Alpha & $t$-stat & $R_{\text {adj }}^{2}$ & Mean & Alpha & $t$-stat & $R_{\mathrm{adj}}^{2}$ \\
\hline High & 0.54 & -0.84 & -1.17 & 28.93 & -0.22 & -1.40 & -2.25 & 26.60 \\
\hline 4 & -0.08 & -1.68 & -2.45 & 38.42 & -0.80 & -2.08 & -2.81 & 23.32 \\
\hline 3 & -0.14 & -1.60 & -1.82 & 24.80 & -0.78 & -2.08 & -3.21 & 30.44 \\
\hline 2 & -0.51 & -1.77 & -2.69 & 27.98 & 0.12 & -1.00 & -2.12 & 35.46 \\
\hline \multirow[t]{2}{*}{ Low } & -0.65 & -1.49 & -3.87 & 30.48 & 0.63 & -0.72 & -1.31 & 38.76 \\
\hline & \multicolumn{4}{|c|}{ Panel B: BH sorted by $\beta_{\text {seq }}$} & \multicolumn{4}{|c|}{ Panel E: BH sorted by $\left|\mu_{\text {seq }}\right|$} \\
\hline Group & Mean & Alpha & $t$-stat & $R_{\text {adj }}^{2}$ & Mean & Alpha & $t$-stat & $R_{\text {adj }}^{2}$ \\
\hline High & 2.16 & 1.86 & 4.68 & 6.10 & 3.67 & 2.97 & 4.32 & 8.97 \\
\hline 4 & 2.06 & 1.96 & 4.66 & 0.31 & 2.80 & 2.36 & 4.26 & 4.13 \\
\hline 3 & 1.60 & 1.30 & 2.26 & 2.57 & 1.76 & 1.58 & 4.31 & 2.29 \\
\hline 2 & 2.04 & 1.46 & 3.31 & 12.90 & 1.00 & 0.75 & 3.49 & 10.47 \\
\hline \multirow[t]{2}{*}{ Low } & 1.86 & 1.61 & 5.74 & 7.15 & 0.36 & 0.30 & 1.52 & 0.64 \\
\hline & \multicolumn{4}{|c|}{ Panel C: FM sorted by $\beta_{\text {seq }}$} & \multicolumn{4}{|c|}{ Panel F: FM sorted by $\left|\mu_{\text {seq }}\right|$} \\
\hline Group & Mean & Alpha & $t$-stat & $R_{\text {adj }}^{2}$ & Mean & Alpha & $t$-stat & $R_{\text {adj }}^{2}$ \\
\hline High & 2.70 & 1.02 & 1.56 & 44.88 & 3.46 & 1.57 & 2.86 & 50.78 \\
\hline 4 & 1.98 & 0.28 & 0.54 & 51.53 & 2.00 & 0.28 & 0.50 & 48.40 \\
\hline 3 & 1.46 & -0.31 & -0.48 & 43.25 & 0.98 & -0.50 & -1.03 & 47.70 \\
\hline 2 & 1.53 & -0.31 & -0.55 & 49.46 & 1.12 & -0.25 & -0.61 & 48.51 \\
\hline Low & 1.22 & 0.12 & 0.35 & 47.92 & 0.99 & -0.43 & -0.81 & 45.88 \\
\hline
\end{tabular}

This table displays the summary statistics of the return of each factor portfolio. The portfolio is formed on each quintile group of factors sequentially sorted by $\beta_{\text {seq }}$ and $\left|\mu_{\text {seq }}\right|$. The regression alpha of each portfolio, its robust $t$-statistic relative to the stock momentum factor and the percentage adjusted $R^{2}$-value are reported. The average portfolio return (mean) and portfolio alpha are annualized and reported in percentage.

of factor momentum returns.

Above results also lead one to conjecture that sorting factors by absolute return mean may result in a greater tilt towards profitable factors and therefore higher factor momentum returns. Panels D to $\mathrm{F}$ lend support to this claim. In Panel E, both the average return and portfolio alpha in the top quintile is larger in magnitude compared to Panel B with a greater slope across groups, though the robust $t$-statistic decreases slightly from 4.68 to 


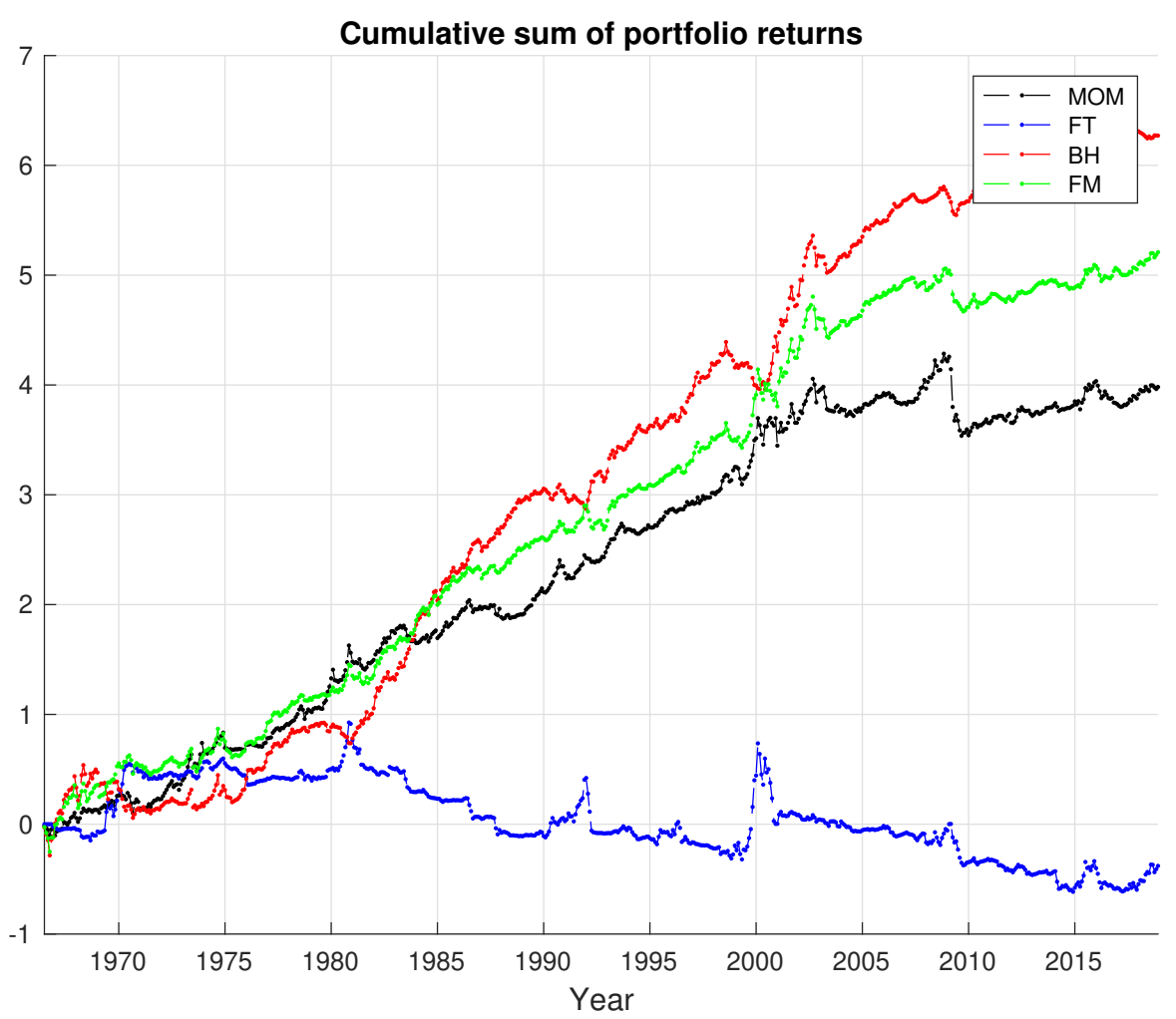

Figure 2: Cumulative return of factor portfolios. This figure displays the cumulative sum of the return of the stock momentum factor and each factor portfolio. MOM is the stock momentum factor. All factor portfolios are formed on the top quintile group of factors sequentially sorted by $\left|\mu_{\text {seq }}\right|$. Each factor portfolio is levered to have the same standard deviation as the stock momentum factor.

4.32. Because of gained tilts towards the most profitable factors, factor momentum in the top quintile produces a statistically significant regression alpha relative to stock momentum with a robust $t$-statistic of $2.86 .^{5}$ It is worth emphasizing that the numbers in Table 1 are rather conservative estimates of the portfolio return; one could practically obtain better performance by restricting to a few extreme factors (Section 3.6).

The return of the factor timing strategy captures a reasonably large fraction of the timevariation of the stock momentum factor. The adjusted $R^{2}$-value of the corresponding spanning regressions is above $20 \%$ for all quintile groups and larger than that for the buy-and-hold

\footnotetext{
${ }^{5}$ For robustness checks, Fama and French (2015) factors (Table A.2) or Hou et al. (2015) factors (Table A.3) are added to above spanning regressisons as additional control variables. The empirical results become less favorable to factor momentum but remain overall consistent.
} 
portfolio. Figure 2 compares the cumulative return of stock momentum with other strategies formed on the top quintile of factors sorted by absolute return mean. Each factor portfolio is levered to have the same standard deviation with the stock momentum factor. The factor timing strategy delivers a negative return most of the time with sharp spikes and drops. The buy-and-hold portfolio, however, isolates the factor momentum profit from its time-series variation and outperforms all other strategies in the risk-adjusted return.

Figure 3 displays the number of total months when each factor is included in the top quintile group of factors sequentially sorted by absolute return mean. It is shown that the quasi-static factor position is not concentrated on a fixed subset of factors, which implies that investors do rebalance the factor position at some time. The most frequently included factors are revenue surprise $(\mathrm{RS})$, return on equity (ROE), R\&D to market (RDM), seasonality (SE1), profitability to market (PMKT) and sales to price (SP). These factors cover the most wellknown types of stock anomalies studied by literature and are held for around 600 months in the entire history.

Other publicly available factors, including investment to asset (IA), beta arbitrage (BAB), mispricing related to management (MGMT) and financing (FIN) are also often included. I therefore also consider public US and global factors summarized in Table A.1 for portfolio formation and document exactly the same finding. These public factors are perceived as the common risk factors of the cross-section and are therefore a sparse representation of the whole universe of stocks or factors. Empirically, the factor timing portfolio and buy-and-hold portfolio have an annual return of $-1.06 \%$ and $4.47 \%$ and Sharpe ratio of -0.21 and 1.23. Combining both components, the factor momentum portfolio only earns an annual return of $3.41 \%$ and Sharpe ratio of 0.71 . Lastly, global factors such as quality (GQMJ), AQR value (GHMLD) and beta arbitrage (GBAB) are also often included. Excluding these factors from the factor zoo results in highly similar results for factor portfolios based on quintile sorts and public factors only. 


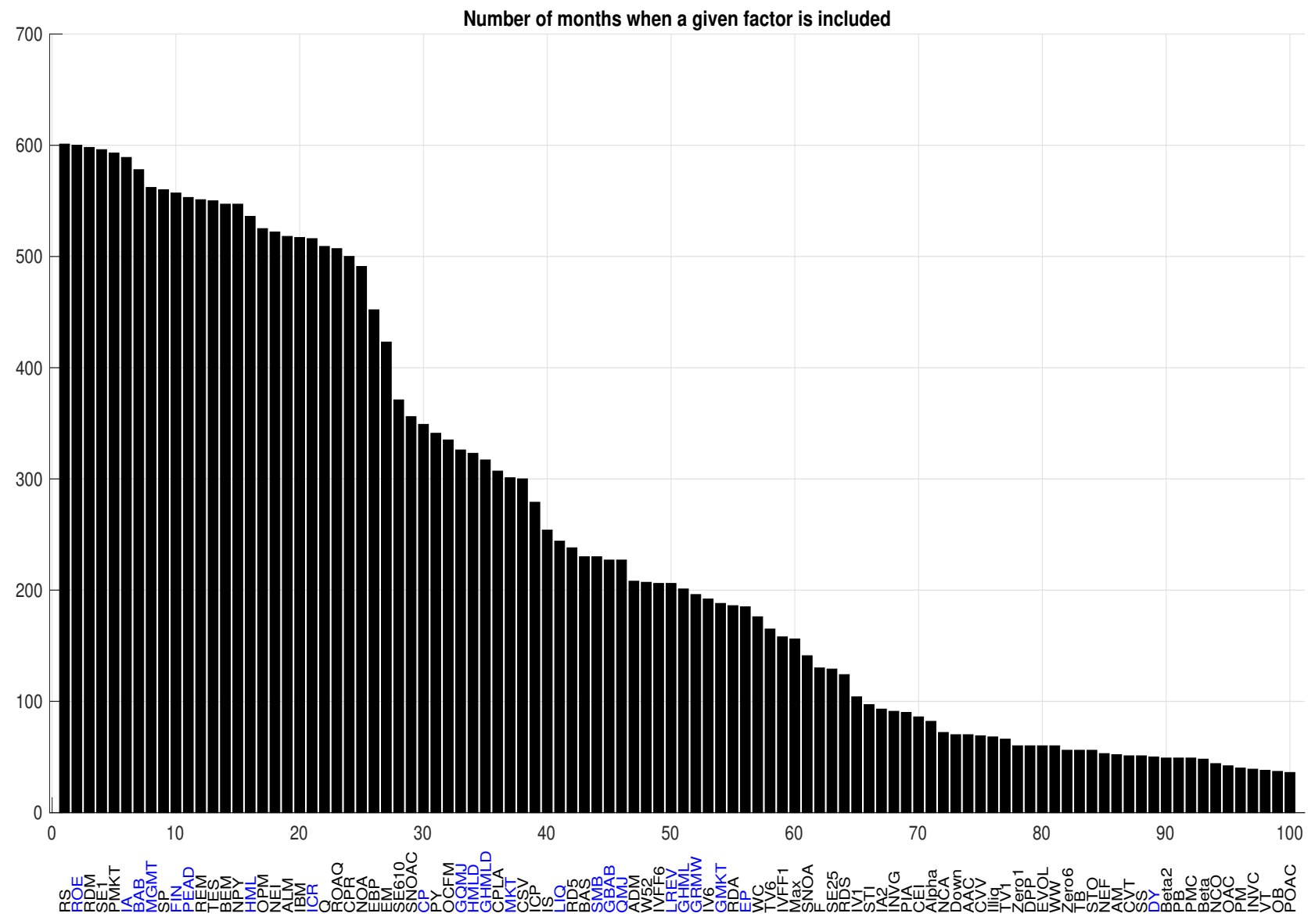

Figure 3: Number of months when a given factor is included. This figure displays the number of months when each factor is included in the top quintile group of factors sequentially sorted by $\left|\mu_{\text {seq }}\right|$. Only top one hundred factors ranked by the number of months is plotted. Factors marked in blue are publicly available factors.

Previous results reveal through sequential factor sorts that the portfolio gain from out-ofsample predictability is empirically weak. Table 2 further suggests that even timing factors that are the most predictable in the entire sample history does not lead to significant returns. Specifically, factors are sorted into quintile groups based on the full-sample estimates of the level of predictability $\left(\beta_{\mathrm{fs}}\right)$ or absolute return mean $\left(\left|\mu_{\mathrm{fs}}\right|\right)$. This is equivalent to assuming that investors observe the entire history of factor returns and form portfolios on the most predictable or profitable factors only. Through this factor sort the factor timing benefit correlates with the level of in-sample predictability. In Panel A, the factor timing portfolio 
Table 2: Factor Portfolio Returns Relative to Stock Momentum: Full-Sample Sorts

\begin{tabular}{|c|c|c|c|c|c|c|c|c|}
\hline \multirow[b]{2}{*}{ Group } & \multicolumn{4}{|c|}{ Panel A: FT sorted by $\beta_{\mathrm{fs}}$} & \multicolumn{4}{|c|}{ Panel D: FT sorted by $\left|\mu_{\mathrm{fs}}\right|$} \\
\hline & Mean & Alpha & $t$-stat & $R_{\mathrm{adj}}^{2}$ & Mean & Alpha & $t$-stat & $R_{\mathrm{adj}}^{2}$ \\
\hline High & 0.51 & -0.32 & -0.72 & 29.99 & -1.26 & -2.63 & -3.81 & 30.89 \\
\hline 4 & 0.05 & -1.46 & -2.18 & 34.10 & -0.66 & -2.50 & -2.37 & 23.95 \\
\hline 3 & -0.12 & -1.30 & -2.12 & 28.17 & -0.62 & -1.69 & -3.74 & 37.33 \\
\hline 2 & -0.29 & -1.77 & -2.35 & 30.15 & -0.03 & -0.94 & -2.26 & 31.30 \\
\hline \multirow[t]{2}{*}{ Low } & -1.13 & -2.37 & -4.32 & 32.17 & 1.49 & 0.44 & 0.98 & 29.83 \\
\hline & \multicolumn{4}{|c|}{ Panel B: BH sorted by $\beta_{\mathrm{fs}}$} & \multicolumn{4}{|c|}{ Panel E: BH sorted by $\left|\mu_{\mathrm{fs}}\right|$} \\
\hline Group & Mean & Alpha & $t$-stat & $R_{\mathrm{adj}}^{2}$ & Mean & Alpha & $t$-stat & $R_{\mathrm{adj}}^{2}$ \\
\hline High & 2.55 & 2.22 & 7.21 & 11.37 & 4.91 & 4.50 & 7.37 & 4.27 \\
\hline 4 & 2.31 & 2.46 & 5.47 & 0.80 & 2.91 & 2.71 & 3.51 & 0.37 \\
\hline 3 & 1.55 & 1.16 & 3.16 & 7.97 & 1.82 & 1.58 & 5.62 & 7.17 \\
\hline 2 & 1.70 & 0.98 & 2.44 & 24.98 & 0.78 & 0.48 & 1.98 & 11.56 \\
\hline \multirow[t]{2}{*}{ Low } & 1.48 & 1.14 & 3.04 & 6.16 & -0.68 & -1.16 & -3.11 & 11.51 \\
\hline & \multicolumn{4}{|c|}{ Panel C: FM sorted by $\beta_{\mathrm{fs}}$} & \multicolumn{4}{|c|}{ Panel F: FM sorted by $\left|\mu_{\mathrm{fs}}\right|$} \\
\hline Group & Mean & Alpha & $t$-stat & $R_{\mathrm{adj}}^{2}$ & Mean & Alpha & $t$-stat & $R_{\mathrm{adj}}^{2}$ \\
\hline High & 3.06 & 1.90 & 4.66 & 47.44 & 3.66 & 1.87 & 4.04 & 59.29 \\
\hline 4 & 2.36 & 1.01 & 1.96 & 38.61 & 2.24 & 0.21 & 0.32 & 47.26 \\
\hline 3 & 1.42 & -0.14 & -0.28 & 47.61 & 1.20 & -0.10 & -0.25 & 49.47 \\
\hline 2 & 1.41 & -0.79 & -1.33 & 57.30 & 0.75 & -0.46 & -1.20 & 50.31 \\
\hline Low & 0.35 & -1.23 & -2.59 & 53.74 & 0.81 & -0.73 & -1.48 & 48.37 \\
\hline
\end{tabular}

This table displays the summary statistics of the return of each factor portfolio. The portfolio is formed on each quintile group of factors sorted by $\beta_{\mathrm{fs}}$ and $\left|\mu_{\mathrm{fs}}\right|$. The regression alpha of each portfolio, its robust $t$-statistic relative to the stock momentum factor and the percentage adjusted $R^{2}$-value are reported. The average portfolio return (mean) and portfolio alpha are annualized and reported in percentage.

of the top quintile group has a return mean of $0.51 \%$ and regression alpha of $-0.32 \%$ with a robust $t$-statistic of -0.72 . The empirical performance is not fundamentally different from that of the sequentially sorted portfolio in Table 1. In Panels B and E, the buy-and-hold portfolio continues to outperform by producing larger and more significant returns. These results show that the in-sample predictability is also too weak to produce timing benefits.

To examine whether previous sequential sorts by return mean produce superior returns 
compared to other combination of factors, I draw 10,000 simulations where each time 42 factors (one-fifth of the population) are randomly selected with equal probability and without replacement, and used to construct the factor timing portfolio and buy-and-hold portfolio. Figure 4 compares the average return of the simulated portfolios with above sorts. It is shown that the buy-and-hold portfolio carrying a larger fraction of the total return is a universal phenomenon among all combinations of factors. Moreover, the buy-and-hold portfolio sequentially sorted by return mean produces a high return that is hard to reach for all simulated buy-and-hold portfolios. The factor timing portfolio sorted by $\beta_{\text {seq }}$ outperforms almost all simulated factor timing portfolios due to its maximum tilt towards predictable factors, but the return is small compared to the buy-and-hold portfolios.

\subsection{Explaining Stock Momentum}

Ehsani and Linnainmaa (2019) argue that stock momentum stems from factor momentum through the lens of a factor structure, and empirically find that factor momentum subsumes stock momentum. I find that the explanatory power of the momentum of sequentially sorted factors is also large compared to other single factors in the zoo. Panel A of Figure 5 displays the estimation results from regressing stock momentum returns on each single factor through a bivariate scatter plot. A small robust $t$-statistic of the regression intercept implies that the right-hand side factor explains the level of stock momentum returns, and a large adjusted $R^{2}$-value suggests that the right-hand side factor explains its time-variation. It is shown that some factors such as PEAD, GQMJ and GBAB subsume stock momentum returns, but they can hardly explain its time-variation. Some other factors, for instance, the monthly updated value factor (HMLD, Asness and Frazzini, 2013), share price level (Price, Blume and Husic, 1973) and 52-week high (W52, George and Hwang, 2004) may explain the time-variation, but the excess return of stock momentum relative to these factors remains statistically significant with large $t$-statistics. One can also see that the factor timing portfolio captures 


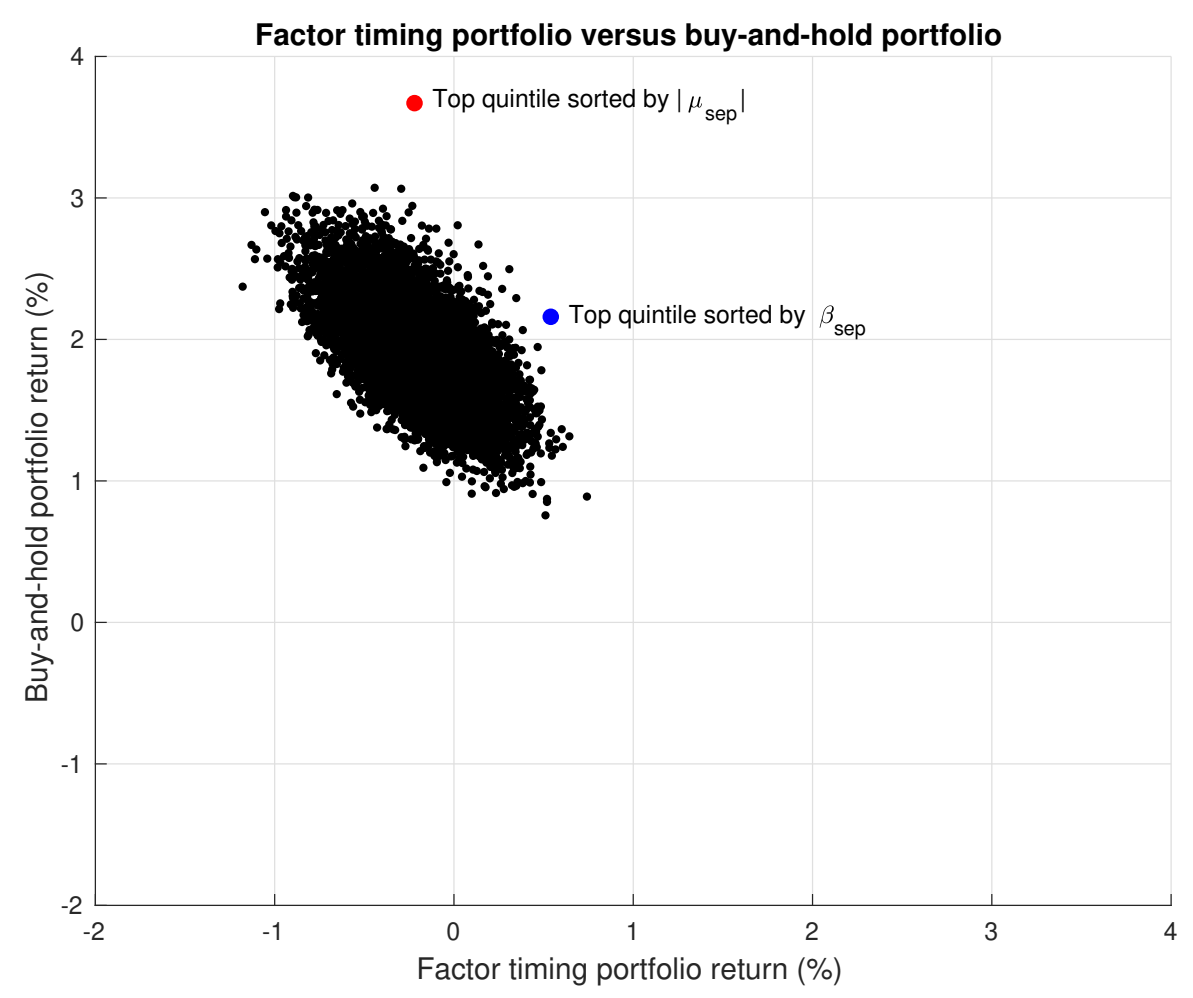

Figure 4: Bivariate scatter plot of factor portfolio returns. This figure displays the bivariate scatter plot of the average return of the factor timing portfolio and buy-and-hold portfolio. In each of 10,000 simulations, 42 factors are randomly selected with equal probability and without replacement, and are used to contruct the factor timing portfolio and buy-andhold portfolio. The factor portfolios formed on the top quintile of factors sequentially sorted by $\beta_{\text {seq }}$ and $\left|\mu_{\text {seq }}\right|$ are also displayed. The average return is annualized and reported in percentage.

the time-variation, whereas the buy-and-hold portfolio explains the level of stock momentum returns. Combining both components, factor momentum captures stock momentum in both dimensions, and sorting factors by return mean performs better.

Arnott et al. (2019) and Ehsani and Linnainmaa (2019) argue that the factor momentum profit is not subject to selection bias. Panel B of Figure 5 compares above sequentially sorted factor momentum portfolios with 10,000 simulated factor momentum portfolios formed on 42 randomly selected factors. It is shown that only half of the total portfolios subsume stock momentum with a robust $t$-statistic of the regression alpha below 2 . The choice of factors is therefore critical to explaining stock momentum. When factors are sorted by return mean, 

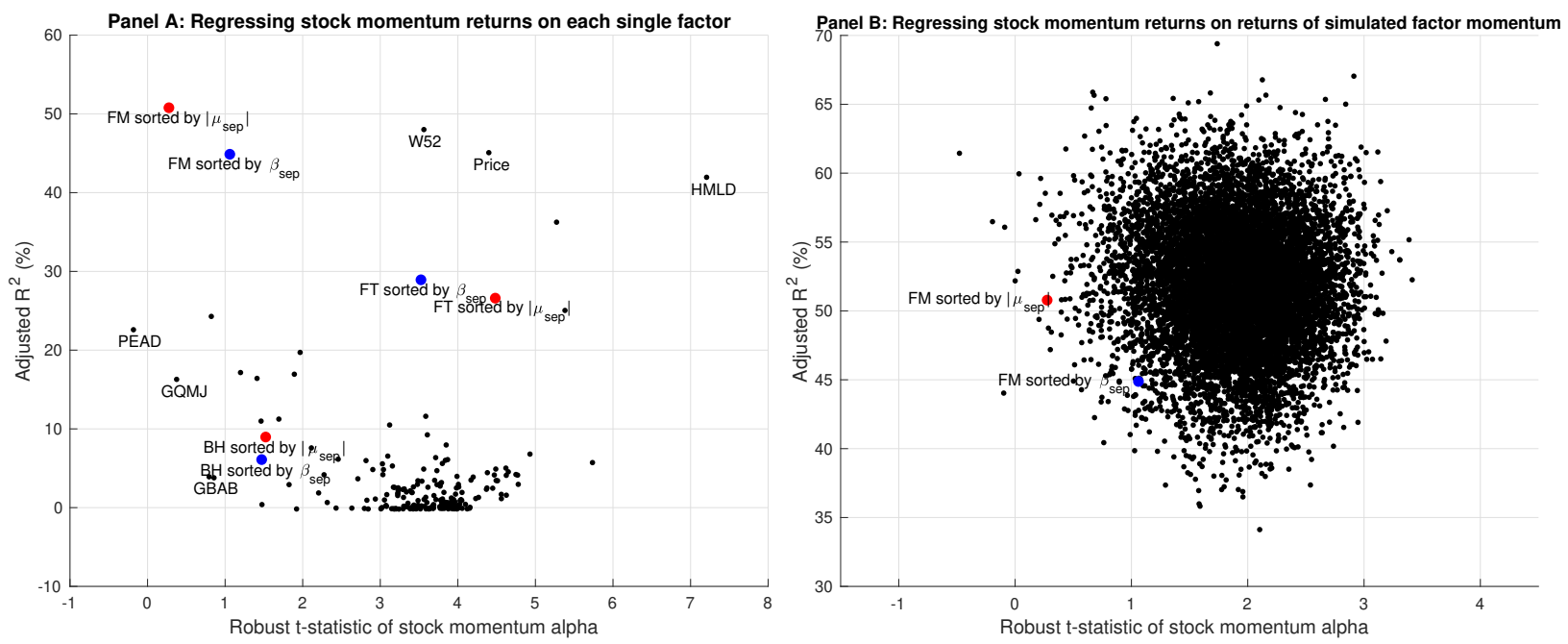

Figure 5: Comparing the explantory power of factor portfolios with other factors. This figure displays the bivariate scatter plot of the robust $t$-statistic of stock momentum alpha and adjusted $R^{2}$-value when stock momentum returns are regressed on (1) each single factor in the zoo, and (2) returns of simulated factor momentum portfolios. In each of 10,000 simulations, 42 factors are randomly selected with equal probability and without replacement, and are used to construct the factor momentum portfolio. Estimates for factor portfolios formed on the top quintile of factors sequentially sorted by $\beta_{\text {seq }}$ and $\left|\mu_{\text {seq }}\right|$ are also displayed.

factor momentum stands among the strongest ones in explaining stock momentum.

\subsection{Sensitivity Analysis}

Previous results indicate that the buy-and-hold strategy and factor momentum strategy formed on the top quintile of factors earn an excess return relative to the stock momentum factor with large robust $t$-statistics. In this section, I explore the empirical performance by varying the number of included factors.

Each month, a fixed number of top factors ranked by return mean are used to form each factor portfolio, with the number of factors increasing from 1 to 210 . For each portfolio, Figure 6 displays the average return, Sharpe ratio, excess return relative to the stock momentum factor and its robust $t$-statistic. The buy-and-hold strategy dominates the other two strategies in all above measures. In particular, Panels A and C suggest that the buy-and-hold 
strategy contributes dominantly to the total return of factor momentum. All measures for the factor timing strategy are negative, which suggests that the portfolio gain from time-series predictability is weak for all construction.

The risk-adjusted return of the buy-and-hold portfolio is prominent for a wide range of the

number of included factors. When only a few factors are included, all measures of portfolio performance increase sharply. As the number of factors continues to grow, the Sharpe ratio and robust $t$-statistic of the buy-and-hold portfolio decrease and start to bounce back further as there are greater diversification benefits, whereas those for the factor momentum portfolio continue to decay. Overall, the Sharpe ratio of the buy-and-hold strategy stays above 0.8, and its robust $t$-statistic stays above 4 .

Noteworthy, the Sharpe ratio and robust $t$-statistic reach the bottom when the top quintile of all factors are incorporated. The estimates in Table 1 are therefore lower bounds of all possible results. Among all choices of the investment set size, the buy-and-hold strategy and factor momentum perform the best when ten to twenty factors are included for portfolio formation, with the maximum Sharpe ratios being 1.1 and 0.8 and the maximum robust t-statistics being 6.5 and 3.6, respectively.

\subsection{Other Horizons}

The previous strategies rebalance the portfolios at a monthly frequency based on the prior oneyear return skipping one month. This section extends previous studies to other formation and holding periods up to one year. Specifically, the factor timing strategy and factor momentum strategy are formed based on the prior $k$-month return and held for $h$ months, with $k$ and $h$ taking values of $1,3,6,9$ and 12 . When the holding period is longer than one month, the holding-period returns overlap. This paper uses the Jegadeesh and Titman (1993) approach to construct nonoverlapping monthly portfolio returns, and uses the example provided by Arnott et al. (2019) for illustration. Consider a holding period of $h=3$ months. In January 
1999, for instance, there are monthly returns of three strategies, each of which is formed in October, November and December 1998. The portfolio return in January 1999 is the average return of these three strategies. The economic interpretation is that one-third of the portfolio is rebalanced in the end of each month. This procedure also reshapes the data to avoid the use of overlapping returns.

Figure 7 compares the risk-adjusted return, including the Sharpe ratio and robust $t$-statistic of the excess return to stock momentum. The excess return is defined as the intercept from regressing portfolio returns on the stock momentum factor. The buy-and-hold portfolio stands out for all formation and holding horizons. In Panels A and B, the risk-adjusted return of the factor timing portfolio is negative except for a few combinations including the $1 / 1$ construction, and the magnitude is economically small. The time-series predictability therefore can hardly transmit into portfolio returns for any formation and holding period considered so far. Panels $\mathrm{C}$ and D show that the risk-adjusted return of the buy-and-hold portfolio is consistent with Table 1 and similar for different combinations by nature. Panels E and F display the riskadjusted return of the factor momentum strategy. The Sharpe ratio is greater than 0.5 for combinations such as $1 / 1,12 / 1$ and $1 / 12$, but generally smaller than that of the buy-and-hold strategy. The robust $t$-statistic is larger than that of the buy-and-hold strategy only for the $1 / 1$ construction (6.3). This is due to the fact that construction of the stock momentum factor skips the most recent month, whereas the $1 / 1$ factor momentum portfolio is formed based on the prior one-month return.

\subsection{One-Month Formation and Holding Periods}

Figure 7 indicates that the $1 / 1$ factor momentum portfolio is not subsumed by the stock momentum factor. This section presents more results for the $1 / 1$ construction, with relevant regression estimates for model (6) displayed in Figure 8. Panel A shows that the estimated regression coefficients become more concentrated than previous estimates using one-year re- 
turn. In Panel B, the out-of-sample predictability becomes stronger compared to Figure 1, with more than half of the total factors delivering a positive $R_{\mathrm{oos}}^{2}$-value.

I then follow Arnott et al. (2019) and benchmark all 1/1 factor portfolios against $1 / 1$ crosssectional industry momentum (IMOM) formed on Fama-French 17-industry portfolios. The industry momentum portfolio goes long (short) in the top (bottom) three industry portfolios ranked by the return in the prior month and is rebalanced at a monthly frequency. Table 3 summarizes the empirical performance of the sorted $1 / 1$ factor portfolios and suggests that the return of the buy-and-hold portfolio remains prominent. Panel A documents an improvement in the empirical performance of factor timing portfolios compared to Table 1: The average return and excess return relative to industry momentum become positive for four quintile groups. Such an improvement is due to the greater out-of-sample predictability at the onemonth formation period. However, the excess return remains statistically insignificant with a maximum $t$-statistic of 1.01 . In Panel B, although the factors are sorted by $\beta_{\text {seq }}$, the return appears to be significant for all quintile buy-and-hold portfolios with a minimum $t$-statistic of 2.96 .

The buy-and-hold portfolio sorted by return mean continues to outperform other strategies. In Panel E, one can see that both the average return and excess return increase in absolute return mean. Among all, the buy-and-hold portfolio formed on the top quintile earns the highest level of return relative to other portfolios in Panels A, B, C and D. The average return is $3.99 \%$ per annum and the regression alpha is $3.68 \%$ with a robust $t$-statistic of 5.31 . Further, a comparison between Panels $\mathrm{C}$ and $\mathrm{F}$ shows that sorting factors by return mean produces a greater factor momentum return, with an average return of $4.52 \%$ and a regression alpha with $t$-statistic of 5.03 . 
Table 3: Factor Portfolio Returns Relative to Industry Momentum

\begin{tabular}{|c|c|c|c|c|c|c|c|c|}
\hline \multirow[b]{2}{*}{ Group } & \multicolumn{4}{|c|}{ Panel A: FT sorted by $\beta_{\text {seq }}$} & \multicolumn{4}{|c|}{ Panel D: FT sorted by $\left|\mu_{\text {seq }}\right|$} \\
\hline & Mean & Alpha & $t$-stat & $R_{\mathrm{adj}}^{2}$ & Mean & Alpha & $t$-stat & $R_{\text {adj }}^{2}$ \\
\hline High & 1.90 & 0.77 & 1.01 & 13.81 & 0.53 & -0.76 & -0.90 & 11.49 \\
\hline 4 & 1.63 & 0.43 & 0.45 & 12.56 & 0.41 & -0.78 & -0.94 & 12.31 \\
\hline 3 & 1.80 & 0.45 & 0.51 & 17.49 & 1.08 & 0.02 & 0.03 & 14.85 \\
\hline 2 & 1.19 & 0.09 & 0.17 & 20.64 & 1.51 & 0.47 & 1.00 & 20.73 \\
\hline \multirow[t]{2}{*}{ Low } & -0.32 & -1.08 & -2.98 & 19.40 & 2.28 & 1.02 & 1.98 & 24.65 \\
\hline & \multicolumn{4}{|c|}{ Panel B: BH sorted by $\beta_{\text {seq }}$} & \multicolumn{4}{|c|}{ Panel E: BH sorted by $\left|\mu_{\text {seq }}\right|$} \\
\hline Group & Mean & Alpha & $t$-stat & $R_{\mathrm{adj}}^{2}$ & Mean & Alpha & $t$-stat & $R_{\text {adj }}^{2}$ \\
\hline High & 1.63 & 1.42 & 2.96 & 1.14 & 3.99 & 3.68 & 5.31 & 1.01 \\
\hline 4 & 2.25 & 1.97 & 3.19 & 1.34 & 2.87 & 2.51 & 4.57 & 2.04 \\
\hline 3 & 1.90 & 1.69 & 3.25 & 1.06 & 1.79 & 1.58 & 4.71 & 2.17 \\
\hline 2 & 1.73 & 1.63 & 5.16 & 0.71 & 1.05 & 0.90 & 3.99 & 2.83 \\
\hline \multirow[t]{2}{*}{ Low } & 2.07 & 1.92 & 7.73 & 2.47 & 0.34 & 0.30 & 1.64 & 0.06 \\
\hline & \multicolumn{4}{|c|}{ Panel C: FM sorted by $\beta_{\text {seq }}$} & \multicolumn{4}{|c|}{ Panel F: FM sorted by $\left|\mu_{\text {seq }}\right|$} \\
\hline Group & Mean & Alpha & $t$-stat & $R_{\mathrm{adj}}^{2}$ & Mean & Alpha & $t$-stat & $R_{\text {adj }}^{2}$ \\
\hline High & 3.52 & 2.19 & 3.91 & 25.47 & 4.52 & 2.92 & 5.03 & 25.49 \\
\hline 4 & 3.88 & 2.40 & 3.71 & 25.64 & 3.28 & 1.73 & 2.80 & 28.78 \\
\hline 3 & 3.70 & 2.14 & 3.38 & 29.15 & 2.87 & 1.60 & 3.16 & 24.41 \\
\hline 2 & 2.92 & 1.72 & 3.50 & 26.83 & 2.57 & 1.37 & 3.03 & 27.98 \\
\hline Low & 1.75 & 0.84 & 2.56 & 31.44 & 2.62 & 1.32 & 2.85 & 28.79 \\
\hline
\end{tabular}

This table displays the summary statistics of the return of each factor portfolio. The portfolio is formed on each quintile group of factors sequentially sorted by $\beta_{\text {seq }}$ and $\left|\mu_{\text {seq }}\right|$. The regression alpha of each portfolio, its robust $t$-statistic relative to industry momentum and the percentage adjusted $R^{2}$-value are reported. The average portfolio return (mean) and portfolio alpha are annualized and reported in percentage.

\section{Post-Publication Return}

If the factor momentum profit stems from a quasi-static factor postion, the publication of factors may result in a decay of its performance as these stock anomalies may have been exploited by arbitrageurs since publication or are simply statistical artifacts. Following McLean and Pontiff (2016), the publication date is defined as the year and month when the anomaly 
is published in academic journals. For unpublished working papers, the publication date is defined as the earliest date when the paper is uploaded to the public domain such as SSRN. Further, it is assumed that investors become aware of each anomaly by the end of the corresponding publication month. McLean and Pontiff (2016) find that the post-publication decay in factor returns is robust to various definitions of the publication date.

For empirical illustration, each factor is required to have a minimum of 36 monthly observations both pre- and post-publication. This filter rules out 20 factors, leaving 190 factors in the sample set. Each factor is rotated to have a positive pre-publication average return. Panel A of Figure 9 compares the average pre- and post-publication return and find that the return of 147 factors decays, and that 57 factors have a negative average return after being published. ${ }^{6}$ To compare, the stock momentum factor has an average annualized return of $10.6 \%$ and $5.4 \%$ before and after the publication of Jegadeesh and Titman (1993), with a robust $t$-statistic of 4.7 and 1.5, respectively. An important reason that the stock momentum return becomes insignificant post-publication is that momentum crashes (Daniel and Moskowitz, 2016) occur during March to May in 2009 (Figure 10); if the returns in the crash period are excluded, the post-publication return increases to $7.7 \%$ per annum with a robust $t$-statistic of 3 .

Panel B of Figure 9 compares the OLS estimates of the prediction coefficients in equation (6) pre- and post-publication and reveals that there is a mild decay in the level of timeseries predictability. The estimated coefficient is positive for 122 out of 190 factors prepublication and for 95 factors post-publication. For factors with positive prediction coefficients pre-publication, 25 of them have a smaller post-publication estimate. The publication effect on the average return and their predictability is robust when they are measured by the respective robust $t$-statistics.

\footnotetext{
${ }^{6}$ In a regression model with the factor fixed effect and post-publication dummy

$$
F_{i, t}=\alpha_{i}+\mathbf{I}_{t>\text { pub date }_{i}} \beta+\epsilon_{i, t},
$$

the robust $t$-statistic of the post-publication dummy is -8.1 and suggests that the publication effect is strong in the entire cross-section of stock return factors.
} 
To study whether and how the publication of anomalies affects the empirical performance of above factor portfolios, I consider the subperiod from December 1989 and January 1995 to December 2018, respectively, where there are a minimum of 21 and 42 published factors. Given that the stock momentum factor is published by Jegadeesh and Titman (1993) in March 1993, these sample periods largely overlap with the post-publication period of stock momentum.

Each month, each factor portfolio is formed on top 21 or 42 published factors ranked by return mean. They are further compared with the top decile and quintile portfolios based on all factors as described in Section 3.4. Figure 10 displays the cumulative return of all portfolios when each of them is levered to have the same standard deviation as the stock momentum factor. It is shown that in all panels, the buy-and-hold portfolio outperforms other portfolios by producing the highest cumulative return, whereas the cumulative return of the factor timing portfolios eventually becomes negative. The buy-and-hold portfolio return decays when only published factors are used for portfolio formation. The momentum strategy of published factors becomes indistinguishable from the stock momentum factor, which suggests that, accounting for the publication effect, factor momentum can hardly outperform the stock momentum factor.

The buy-and-hold portfolios of published factors, however, remain outperforming the stock momentum factor. The quantitative statistics are displayed in Table 4. The Sharpe ratio becomes smaller when only published factors are considered for portfolio formation but remains larger than that of other strategies. For instance, the Sharpe ratio decreases from 1.26 to 0.80 and from 0.78 to 0.60 for each construction. Among other strategies formed on published factors, the largest Sharpe ratio is achieved by the momentum of 21 published factors (0.49). For the buy-and-hold portfolio of published factors, the excess return relative to the stock momentum factor remains statistically significant with a robust $t$-statistic above 2 . Moreover, the buy-and-hold portfolios produce the most favorable kurtosis among all portfolios and suggest that they are not subject to severe crashes. Lastly, comparing both constructions suggests 
Table 4: Portfolios of All and Published Factors I

\begin{tabular}{lrrrrrrrr}
\hline 21 factors & Mean & Std & \multicolumn{1}{c}{ SR } & Skew & Kurt & Alpha & $t$-stat & $R_{\text {adj }}^{2}$ \\
\hline FT (all) & -1.13 & 4.49 & -0.25 & 0.46 & 12.72 & -2.15 & -2.78 & 33.70 \\
BH (all) & 4.69 & 3.72 & 1.26 & -0.50 & 9.76 & 4.08 & 5.81 & 17.02 \\
FM (all) & 3.56 & 5.13 & 0.70 & -0.27 & 7.91 & 1.93 & 2.99 & 65.86 \\
FT (published) & 0.10 & 5.12 & 0.02 & 0.75 & 14.65 & -1.04 & -1.15 & 32.29 \\
BH (published) & 2.51 & 3.13 & 0.80 & -0.17 & 5.00 & 2.16 & 3.30 & 7.54 \\
FM (published) & 2.61 & 5.34 & 0.49 & 0.69 & 10.96 & 1.13 & 1.44 & 50.25 \\
MOM & 6.40 & 16.36 & 0.39 & -1.53 & 14.37 & & & \\
\hline 42 factors & Mean & Std & SR & Skew & Kurt & Alpha & $t$-stat & $R_{\text {adj }}^{2}$ \\
\hline FT (all) & -0.33 & 5.11 & -0.07 & 1.12 & 13.14 & -1.23 & -1.27 & 33.73 \\
BH (all) & 3.42 & 4.36 & 0.78 & 0.10 & 6.33 & 2.97 & 3.03 & 11.23 \\
FM (all) & 3.09 & 5.57 & 0.55 & 0.36 & 8.26 & 1.74 & 2.13 & 63.94 \\
FT (published) & -0.21 & 4.97 & -0.04 & 1.37 & 14.72 & -1.17 & -1.33 & 40.29 \\
BH (published) & 1.68 & 2.80 & 0.60 & -0.39 & 5.63 & 1.38 & 2.10 & 12.12 \\
FM (published) & 1.47 & 5.36 & 0.27 & 0.82 & 13.97 & 0.21 & 0.29 & 59.99 \\
MOM & 5.25 & 17.39 & 0.30 & -1.50 & 13.47 & & & \\
\hline
\end{tabular}

This table displays the summary statistics of the return of each factor portfolio. Each portfolio is formed on the set of top 21 or 42 factors ranked by $\left|\mu_{\text {seq }}\right|$. The average portfolio return (mean) and standard deviation are annualized and reported in percentage. SR is the annualized Sharpe ratio. The regression alpha of each portfolio, its robust $t$-statistic relative to the stock momentum factor and the percentage adjusted $R^{2}$-value are reported. The sample period extends from (December 1989) January 1995 to December 2018, where there are a minimum of 21 (42) published factors.

that restricting to a small number of profitable factors results in better portfolio performance.

Figure 11 further compares above portfolios of published factors with each single factor and indicates that the empirical performance remains outstanding post-publication. The risk-adjusted return, including the Sharpe ratio and robust $t$-statistic of the regression alpha relative to the stock momentum factor, are displayed in a bivariate scatter plot. In Panel A, factors published before January 1995 are scattered, with the estimates obtained from data in the same sample period as the momentum of 42 published factors (January 1995 to December 2018). In Panel B, estimation is based on all post-publication data, where a minimum of 120 monthly returns are required to form the estimate. In both figures, the buy-and-hold portfolios 
stand among the best performing ones in the Sharpe ratio and excess return relative to stock

momentum. For instance, Panel B shows that only SE610 (Heston and Sadka, 2008) has a Sharpe ratio greater than that of the buy-and-hold portfolio of 21 published factors; aside from it, only PEAD has a greater excess return relative to the stock momentum factor. The factor timing portfolios and factor momentum portfolios, however, underperform many published factors.

Lastly, Table 5 compares the empirical performance of the $1 / 1$ portfolios formed on all factors and published factors. In reporting the regression alpha, the right-hand side variable is the $1 / 1$ industry momentum return. Similar to previous results, the buy-and-hold portfolio becomes less profitable post-publication but continues to deliver statistically significant excess returns relative to industry momentum. The robust $t$-statistic of the regression alpha decreases from 6.12 to 3.60 for 21 published factors and from 3.32 to 2.48 for 42 published factors. The 1/1 factor momentum portfolio produces greater Sharpe ratios and excess returns compared to the construction in Table 4 .

\section{Conclusion}

In recent literature, factor momentum is perceived as a profitable investment strategy and has important asset pricing implications. This paper explores the source of factor momentum returns. Factor momentum may earn profits from (1) time-series predictability of factor returns and (2) the mean-return channel. The latter channel states that factor momentum could profit from consistently buying (selling) factors with positive (negative) average returns instead of factor timing. This paper documents empirical evidence in favor of the latter channel, contrasting with recent literature supporting the former channel.

To study the source of factor momentum returns, the factor momentum strategy is decomposed into two factor strategies, each of which collects the return from each channel. The 
Table 5: Portfolios of All and Published Factors II

\begin{tabular}{llllrrrrr}
\hline 21 factors & Mean & Std & SR & Skew & Kurt & Alpha & $t$-stat & $R_{\text {adj }}^{2}$ \\
\hline FT (all) & 0.01 & 5.98 & 0.00 & 1.08 & 13.77 & -0.86 & -0.92 & 19.34 \\
BH (all) & 4.69 & 3.72 & 1.26 & -0.50 & 9.76 & 4.56 & 6.12 & 0.91 \\
FM (all) & 4.70 & 5.39 & 0.87 & 0.53 & 7.91 & 3.70 & 5.63 & 31.92 \\
FT (published) & 0.47 & 5.42 & 0.09 & 0.04 & 12.04 & -0.28 & -0.26 & 17.35 \\
BH (published) & 2.51 & 3.13 & 0.80 & -0.17 & 5.00 & 2.43 & 3.60 & 0.28 \\
FM (published) & 2.98 & 4.85 & 0.61 & 0.56 & 8.70 & 2.15 & 2.72 & 26.46 \\
IMOM & 5.42 & 16.48 & 0.33 & 0.46 & 4.54 & & & \\
\hline 42 factors & Mean & Std & SR & Skew & Kurt & Alpha & $t$-stat & $R_{\text {adj }}^{2}$ \\
\hline FT (all) & 0.55 & 6.75 & 0.08 & 0.42 & 13.63 & 0.01 & 0.01 & 17.53 \\
BH (all) & 3.42 & 4.36 & 0.78 & 0.10 & 6.33 & 3.37 & 3.32 & -0.00 \\
FM (all) & 3.97 & 5.60 & 0.71 & 0.40 & 7.12 & 3.38 & 4.20 & 30.51 \\
FT (published) & 1.42 & 5.65 & 0.25 & 0.99 & 10.26 & 0.93 & 0.79 & 20.26 \\
BH (published) & 1.68 & 2.80 & 0.60 & -0.39 & 5.63 & 1.63 & 2.48 & 0.54 \\
FM (published) & 3.10 & 4.96 & 0.62 & 0.97 & 9.94 & 2.56 & 2.96 & 32.14 \\
IMOM & 3.29 & 17.24 & 0.19 & 0.54 & 4.50 & & & \\
TMOblat & & & & & & &
\end{tabular}

This table displays the summary statistics of the return of each factor portfolio. Each portfolio is formed on the set of top 21 or 42 factors ranked by $\left|\mu_{\text {seq }}\right|$. The average portfolio return (mean) and standard deviation are annualized and reported in percentage. SR is the annualized Sharpe ratio. The regression alpha of each portfolio, its robust $t$-statistic relative to industry momentum and the percentage adjusted $R^{2}$-value are reported. The sample period extends from (December 1989) January 1995 to December 2018, where there are a minimum of 21 (42) published factors.

return from the latter channel is collected by a quasi-static position, which is called buy-andhold portfolio. The buy-and-hold portfolio earns a dominant fraction of the total return of factor momentum. This empirical finding is robust to portfolio formation based on 210 factors and pervasive among published factors.

The empirical methodology and results have broader asset pricing implications. For instance, in analyzing the relation between factor portfolio returns and the stock momentum factor, one does not impose any structural economic assumption beyond a reduced-form factor structure (Arnott et al., 2019). Therefore, the methodology can be also used to study (factor) momentum in other asset classes such as foreign exchange rates, corporate bonds, etc, and 
further issues therein. 


\section{References}

Abarbanell, Jeffery S, and Brian J Bushee, 1998, Abnormal returns to a fundamental analysis strategy, Accounting Review 19-45.

Almeida, Heitor, and Murillo Campello, 2007, Financial constraints, asset tangibility, and corporate investment, The Review of Financial Studies 20, 1429-1460.

Amaya, Diego, Peter Christoffersen, Kris Jacobs, and Aurelio Vasquez, 2015, Does realized skewness predict the cross-section of equity returns?, Journal of Financial Economics 118, $135-167$.

Amihud, Yakov, 2002, Illiquidity and stock returns: cross-section and time-series effects, Journal of Financial Markets 5, 31-56.

Amihud, Yakov, and Haim Mendelson, 1989, The effects of beta, bid-ask spread, residual risk, and size on stock returns, The Journal of Finance 44, 479-486.

Anderson, Christopher W, and Luis Garcia-Feijóo, 2006, Empirical evidence on capital investment, growth options, and security returns, The Journal of Finance 61, 171-194.

Ang, Andrew, Joseph Chen, and Yuhang Xing, 2006a, Downside risk, The Review of Financial Studies 19, 1191-1239.

Ang, Andrew, Robert J Hodrick, Yuhang Xing, and Xiaoyan Zhang, 2006b, The cross-section of volatility and expected returns, The Journal of Finance 61, 259-299.

Arnott, Robert D, Mark Clements, Vitali Kalesnik, and Juhani T Linnainmaa, 2019, Factor momentum, Technical report.

Asness, Clifford, and Andrea Frazzini, 2013, The devil in HML's details, The Journal of Portfolio Management 39, 49-68. 
Asness, Clifford S, Andrea Frazzini, and Lasse Heje Pedersen, 2019, Quality minus junk, Review of Accounting Studies 24, 34-112.

Asness, Clifford S, Tobias J Moskowitz, and Lasse Heje Pedersen, 2013, Value and momentum everywhere, The Journal of Finance 68, 929-985.

Asness, Clifford S, R Burt Porter, and Ross L Stevens, 2000, Predicting stock returns using industry-relative firm characteristics, Technical report.

Avramov, Doron, Si Cheng, Amnon Schreiber, and Koby Shemer, 2017, Scaling up market anomalies, The Journal of Investing 26, 89-105.

Balakrishnan, Karthik, Eli Bartov, and Lucile Faurel, 2010, Post loss/profit announcement drift, Journal of Accounting and Economics 50, 20-41.

Bali, Turan G, Nusret Cakici, and Robert F Whitelaw, 2011, Maxing out: Stocks as lotteries and the cross-section of expected returns, Journal of Financial Economics 99, 427-446.

Ball, Ray, Joseph Gerakos, Juhani T Linnainmaa, and Valeri Nikolaev, 2016, Accruals, cash flows, and operating profitability in the cross section of stock returns, Journal of Financial Economics 121, 28-45.

Ball, Ray, Joseph Gerakos, Juhani T Linnainmaa, and Valeri Nikolaev, 2019, Earnings, retained earnings, and book-to-market in the cross section of expected returns, Journal of Financial Economics .

Ball, Ray, Joseph Gerakos, Juhani T Linnainmaa, and Valeri V Nikolaev, 2015, Deflating profitability, Journal of Financial Economics 117, 225-248.

Bandyopadhyay, Sati P, Alan G Huang, and Tony S Wirjanto, 2010, The accrual volatility anomaly, Technical report. 
Banz, Rolf W, 1981, The relationship between return and market value of common stocks, Journal of Financial Economics 9, 3-18.

Barbee Jr, William C, Sandip Mukherji, and Gary A Raines, 1996, Do sales-price and debtequity explain stock returns better than book-market and firm size?, Financial Analysts Journal 52, 56-60.

Barry, Christopher B, and Stephen J Brown, 1984, Differential information and the small firm effect, Journal of Financial Economics 13, 283-294.

Barth, Mary E, John A Elliott, and Mark W Finn, 1999, Market rewards associated with patterns of increasing earnings, Journal of Accounting Research 37, 387-413.

Basu, Sanjoy, 1977, Investment performance of common stocks in relation to their priceearnings ratios: A test of the efficient market hypothesis, The Journal of Finance 32, $663-682$.

Belo, Frederico, and Xiaoji Lin, 2012, The inventory growth spread, The Review of Financial Studies 25, 278-313.

Belo, Frederico, Xiaoji Lin, and Santiago Bazdresch, 2014, Labor hiring, investment, and stock return predictability in the cross section, Journal of Political Economy 122, 129-177.

Bernard, Victor L, and Jacob K Thomas, 1990, Evidence that stock prices do not fully reflect the implications of current earnings for future earnings, Journal of Accounting and Economics 13, 305-340.

Bhandari, Laxmi Chand, 1988, Debt/equity ratio and expected common stock returns: Empirical evidence, The Journal of Finance 43, 507-528.

Black, Fischer, Michael C Jensen, Myron Scholes, et al., 1972, The capital asset pricing model: Some empirical tests, Studies in the theory of capital markets 81, 79-121. 
Blume, Marshall E, and Frank Husic, 1973, Price, beta, and exchange listing, The Journal of Finance 28, 283-299.

Boudoukh, Jacob, Roni Michaely, Matthew Richardson, and Michael R Roberts, 2007, On the importance of measuring payout yield: Implications for empirical asset pricing, The Journal of Finance 62, 877-915.

Boyer, Brian, Todd Mitton, and Keith Vorkink, 2010, Expected idiosyncratic skewness, The Review of Financial Studies 23, 169-202.

Bradshaw, Mark T, Scott A Richardson, and Richard G Sloan, 2006, The relation between corporate financing activities, analysts' forecasts and stock returns, Journal of Accounting and Economics 42, 53-85.

Brown, David P, and Bradford Rowe, 2007, The productivity premium in equity returns, Technical report.

Bustamante, M Cecilia, and Andres Donangelo, 2017, Product market competition and industry returns, The Review of Financial Studies 30, 4216-4266.

Campbell, John Y., and Samuel B. Thompson, 2008, Predicting excess stock returns out of sample: Can anything beat the historical average?, The Review of Financial Studies 21, $1509-1531$.

Chan, Kalok, Allaudeen Hameed, and Wilson Tong, 2000, Profitability of momentum stragegies in the international equity markets, Journal of Financial and Quantitative Analysis 35, 153-172.

Chan, Louis KC, Narasimhan Jegadeesh, and Josef Lakonishok, 1996, Momentum strategies, The Journal of Finance 51, 1681-1713.

Chan, Louis KC, Josef Lakonishok, and Theodore Sougiannis, 2001, The stock market valuation of research and development expenditures, The Journal of Finance 56, 2431-2456. 
Chandrashekar, Satyajit, and Ramesh KS Rao, 2006, The productivity of corporate cash holdings and the cross-section of expected stock returns, Technical report.

Chaney, Paul K, and Debra C Jeter, 1994, The effect of deferred taxes on security prices, Journal of Accounting, Auditing \& Finance 9, 91-116.

Chen, Long, and Lu Zhang, 2010, A better three-factor model that explains more anomalies, Journal of Finance 65, 563-595.

Chordia, Tarun, Avanidhar Subrahmanyam, and V Ravi Anshuman, 2001, Trading activity and expected stock returns, Journal of Financial Economics 59, 3-32.

Clark, Todd E., and Kenneth D. West, 2007, Approximately normal tests for equal predictive accuracy in nested models, Journal of Econometrics 138, 291-311.

Conrad, Jennifer, and Gautam Kaul, 1998, An anatomy of trading strategies, The Review of Financial Studies 11, 489-519.

Cooper, Michael J, Huseyin Gulen, and Michael J Schill, 2008, Asset growth and the crosssection of stock returns, The Journal of Finance 63, 1609-1651.

Daniel, Kent, David Hirshleifer, and Lin Sun, 2019, Short- and Long-Horizon Behavioral Factors, The Review of Financial Studies .

Daniel, Kent, and Tobias J Moskowitz, 2016, Momentum crashes, Journal of Financial Economics 122, 221-247.

Daniel, Kent, and Sheridan Titman, 2006, Market reactions to tangible and intangible information, The Journal of Finance 61, 1605-1643.

Datar, Vinay T, Narayan Y Naik, and Robert Radcliffe, 1998, Liquidity and stock returns: An alternative test, Journal of Financial Markets 1, 203-219. 
Davis, James L, Eugene F Fama, and Kenneth R French, 2000, Characteristics, covariances, and average returns: 1929 to 1997, The Journal of Finance 55, 389-406.

De Bondt, Werner FM, and Richard Thaler, 1985, Does the stock market overreact?, The Journal of Finance 40, 793-805.

Desai, Hemang, Shivaram Rajgopal, and Mohan Venkatachalam, 2004, Value-glamour and accruals mispricing: One anomaly or two?, The Accounting Review 79, 355-385.

Dichev, Ilia D, 1998, Is the risk of bankruptcy a systematic risk?, The Journal of Finance 53, $1131-1147$.

Eberhart, Allan C, William F Maxwell, and Akhtar R Siddique, 2004, An examination of long-term abnormal stock returns and operating performance following R\&D increases, The Journal of Finance 59, 623-650.

Ehsani, Sina, and Juhani T Linnainmaa, 2019, Factor momentum and the momentum factor, Technical report, National Bureau of Economic Research.

Fairfield, Patricia M, J Scott Whisenant, and Teri Lombardi Yohn, 2003, Accrued earnings and growth: Implications for future profitability and market mispricing, The Accounting Review 78, 353-371.

Fama, Eugene F, and Kenneth R French, 1992, The cross-section of expected stock returns, The Journal of Finance 47, 427-465.

Fama, Eugene F, and Kenneth R French, 1993, Common risk factors in the returns on stocks and bonds, Journal of Einancial Economics 33, 3-56.

Fama, Eugene F, and Kenneth R French, 2008, Dissecting anomalies, The Journal of Finance 63, 1653-1678. 
Fama, Eugene F, and Kenneth R French, 2015, A five-factor asset pricing model, Journal of Financial Economics 116, 1-22.

Fama, Eugene F, and James D MacBeth, 1973, Risk, return, and equilibrium: Empirical tests, Journal of Political Economy 81, 607-636.

Feng, Guanhao, Stefano Giglio, and Dacheng Xiu, 2019, Taming the factor zoo: A test of new factors, Technical report, National Bureau of Economic Research.

Francis, Jennifer, Ryan LaFond, Per M Olsson, and Katherine Schipper, 2004, Costs of equity and earnings attributes, The accounting review 79, 967-1010.

Frazzini, Andrea, and Lasse Heje Pedersen, 2014, Betting against beta, Journal of Financial Economics 111, 1-25.

Freyberger, Joachim, Andreas Neuhierl, and Michael Weber, 2017, Dissecting characteristics nonparametrically, Technical report, National Bureau of Economic Research.

Geczy, Christopher C, and Mikhail Samonov, 2016, Two centuries of price-return momentum, Financial Analysts Journal 72, 32-56.

George, Thomas J, and Chuan-Yang Hwang, 2004, The 52-week high and momentum investing, The Journal of Finance 59, 2145-2176.

Gopalan, Radhakrishnan, Ohad Kadan, and Mikhail Pevzner, 2012, Asset liquidity and stock liquidity, Journal of Financial and Quantitative Analysis 47, 333-364.

Gorodnichenko, Yuriy, and Michael Weber, 2016, Are sticky prices costly? evidence from the stock market, American Economic Review 106, 165-99.

Goyal, Amit, and Narasimhan Jegadeesh, 2017, Cross-sectional and time-series tests of return predictability: What is the difference?, The Review of Financial Studies 31, 1784-1824. 
Green, Jeremiah, John RM Hand, and X Frank Zhang, 2017, The characteristics that provide independent information about average us monthly stock returns, The Review of Financial Studies 30, 4389-4436.

Gupta, Tarun, and Bryan Kelly, 2019, Factor momentum everywhere, The Journal of Portfolio Management 45, 13-36.

Hafzalla, Nader, Russell Lundholm, and E Matthew Van Winkle, 2011, Percent accruals, The Accounting Review 86, 209-236.

Harvey, Campbell R, Yan Liu, and Heqing Zhu, 2016, ... and the cross-section of expected returns, The Review of Financial Studies 29, 5-68.

Harvey, Campbell R, and Akhtar Siddique, 2000, Conditional skewness in asset pricing tests, The Journal of Finance 55, 1263-1295.

Haugen, Robert A, Nardin L Baker, et al., 1996, Commonality in the determinants of expected stock returns, Journal of Financial Economics 41, 401-439.

He, Zhiguo, Bryan Kelly, and Asaf Manela, 2017, Intermediary asset pricing: New evidence from many asset classes, Journal of Financial Economics 126, 1-35.

Heston, Steven L, and Ronnie Sadka, 2008, Seasonality in the cross-section of stock returns, Journal of Financial Economics 87, 418-445.

Hirshleifer, David, Kewei Hou, Siew Hong Teoh, and Yinglei Zhang, 2004, Do investors overvalue firms with bloated balance sheets?, Journal of Accounting and Economics 38, 297-331.

Hou, Kewei, and Tobias J Moskowitz, 2005, Market frictions, price delay, and the cross-section of expected returns, The Review of Financial Studies 18, 981-1020.

Hou, Kewei, and David T Robinson, 2006, Industry concentration and average stock returns, The Journal of Finance 61, 1927-1956. 
Hou, Kewei, Chen Xue, and Lu Zhang, 2015, Digesting anomalies: An investment approach, The Review of Financial Studies 28, 650-705.

Hou, Kewei, Chen Xue, and Lu Zhang, 2020, Replicating anomalies, The Review of Financial Studies 33, 2019-2133.

Huang, Alan Guoming, 2009, The cross section of cashflow volatility and expected stock returns, Journal of Empirical Finance 16, 409-429.

Huang, Dashan, Jiangyuan Li, Liyao Wang, and Guofu Zhou, 2019, Time-series momentum: Is it there?, Technical report.

Jegadeesh, Narasimhan, 1990, Evidence of predictable behavior of security returns, The Journal of Finance 45, 881-898.

Jegadeesh, Narasimhan, and Joshua Livnat, 2006, Revenue surprises and stock returns, Journal of Accounting and Economics 41, 147-171.

Jegadeesh, Narasimhan, and Sheridan Titman, 1993, Returns to buying winners and selling losers: Implications for stock market efficiency, The Journal of Finance 48, 65-91.

Jensen, Michael C, 1968, The performance of mutual funds in the period 1945-1964, The Journal of Finance 23, 389-416.

Jostova, Gergana, Stanislava Nikolova, Alexander Philipov, and Christof W Stahel, 2013, Momentum in corporate bond returns, The Review of Financial Studies 26, 1649-1693.

Kaldor, Nicholas, 1966, Marginal productivity and the macro-economic theories of distribution: comment on samuelson and modigliani, The Review of Economic Studies 33, 309-319.

Kelly, Bryan, and Hao Jiang, 2014, Tail risk and asset prices, The Review of Financial Studies $27,2841-2871$. 
Lakonishok, Josef, Andrei Shleifer, and Robert W Vishny, 1994, Contrarian investment, extrapolation, and risk, The Journal of Finance 49, 1541-1578.

Lamont, Owen, Christopher Polk, and Jesús Saaá-Requejo, 2001, Financial constraints and stock returns, The Review of Financial Studies 14, 529-554.

Lev, Baruch, and Doron Nissim, 2004, Taxable income, future earnings, and equity values, The Accounting Review 79, 1039-1074.

Lewellen, Jonathan, 2002, Momentum and autocorrelation in stock returns, The Review of Financial Studies 15, 533-564.

Li, Dongmei, 2011, Financial constraints, R\&D investment, and stock returns, The Review of Financial Studies 24, 2974-3007.

Linnainmaa, Juhani T, and Michael R Roberts, 2018, The history of the cross-section of stock returns, The Review of Financial Studies 31, 2606-2649.

Litzenberger, Robert H, and Krishna Ramaswamy, 1979, The effect of personal taxes and dividends on capital asset prices: Theory and empirical evidence, Journal of Financial Economics 7, 163-195.

Liu, Weimin, 2006, A liquidity-augmented capital asset pricing model, Journal of Financial Economics 82, 631-671.

Lo, Andrew W, and A Craig MacKinlay, 1990, When are contrarian profits due to stock market overreaction?, The Review of Financial Studies 3, 175-205.

Lockwood, Larry, and Wikrom Prombutr, 2010, Sustainable growth and stock returns, Journal of Financial Research 33, 519-538.

Lou, Dong, 2014, Attracting investor attention through advertising, The Review of Financial Studies 27, 1797-1829. 
Loughran, Tim, and Jay W Wellman, 2011, New evidence on the relation between the enterprise multiple and average stock returns, Journal of Financial and Quantitative Analysis 46, 1629-1650.

Lyandres, Evgeny, Le Sun, and Lu Zhang, 2008, The new issues puzzle: Testing the investment-based explanation, The Review of Financial Studies 21, 2825-2855.

McLean, R David, and Jeffrey Pontiff, 2016, Does academic research destroy stock return predictability?, The Journal of Finance 71, 5-32.

Menkhoff, Lukas, Lucio Sarno, Maik Schmeling, and Andreas Schrimpf, 2012, Currency momentum strategies, Journal of Financial Economics 106, 660-684.

Moskowitz, Tobias J, and Mark Grinblatt, 1999, Do industries explain momentum?, The Journal of Finance 54, 1249-1290.

Moskowitz, Tobias J, Yao Hua Ooi, and Lasse Heje Pedersen, 2012, Time series momentum, Journal of Financial Economics 104, 228-250.

Nissim, Doron, and Stephen H Penman, 2001, Ratio analysis and equity valuation: From research to practice, Review of Accounting Studies 6, 109-154.

Novy-Marx, Robert, 2011, Operating leverage, Review of Finance 15, 103-134.

Novy-Marx, Robert, 2013, The other side of value: The gross profitability premium, Journal of Financial Economics 108, 1-28.

Okunev, John, and Derek White, 2003, Do momentum-based strategies still work in foreign currency markets?, Journal of Financial and Quantitative Analysis 38, 425-447.

Ou, Jane A, and Stephen H Penman, 1989, Financial statement analysis and the prediction of stock returns, Journal of Accounting and Economics 11, 295-329. 
Palazzo, Berardino, 2012, Cash holdings, risk, and expected returns, Journal of Financial Economics 104, 162-185.

Pástor, L'uboš, and Robert F Stambaugh, 2003, Liquidity risk and expected stock returns, Journal of Political Economy 111, 642-685.

Pástor, Luboš, and Robert F. Stambaugh, 2012, Are stocks really less volatile in the long run?, The Journal of Finance 67, 431-478.

Penman, Stephen H, Scott A Richardson, and Irem Tuna, 2007, The book-to-price effect in stock returns: Accounting for leverage, Journal of Accounting Research 45, 427-467.

Piotroski, Joseph D, et al., 2000, Value investing: The use of historical financial statement information to separate winners from losers, Journal of Accounting Research 38, 1-52.

Pontiff, Jeffrey, and Artemiza Woodgate, 2008, Share issuance and cross-sectional returns, The Journal of Finance 63, 921-945.

Rajgopal, Shivaram, Terry Shevlin, and Mohan Venkatachalam, 2003, Does the stock market fully appreciate the implications of leading indicators for future earnings? evidence from order backlog, Review of Accounting Studies 8, 461-492.

Richardson, Scott A, Richard G Sloan, Mark T Soliman, and Irem Tuna, 2005, Accrual reliability, earnings persistence and stock prices, Journal of Accounting and Economics 39, $437-485$.

Rosenberg, Barr, Kenneth Reid, and Ronald Lanstein, 1985, Persuasive evidence of market inefficiency, The Journal of Portfolio Management 11, 9-16.

Sharpe, William F, 1964, Capital asset prices: A theory of market equilibrium under conditions of risk, The Journal of Finance 19, 425-442.

Shumway, Tyler, 1997, The delisting bias in CRSP data, The Journal of Finance 52, 327-340. 
Sloan, Richard G, 1996, Do stock prices fully reflect information in accruals and cash flows about future earnings?, Accounting Review 289-315.

Sodjahin, William R, 2013, Change in cash-holding policies and stock return predictability in the cross section, Financial Analysts Journal 69, 53-70.

Soliman, Mark T, 2008, The use of dupont analysis by market participants, The Accounting Review 83, 823-853.

Stambaugh, Robert F, and Yu Yuan, 2017, Mispricing factors, The Review of Financial Studies $30,1270-1315$.

Thomas, Jacob, and Frank X Zhang, 2011, Tax expense momentum, Journal of Accounting Research 49, 791-821.

Thomas, Jacob K, and Huai Zhang, 2002, Inventory changes and future returns, Review of Accounting Studies 7, 163-187.

Titman, Sheridan, KC John Wei, and Feixue Xie, 2004, Capital investments and stock returns, Journal of Financial and Quantitative Analysis 39, 677-700.

Tuzel, Selale, 2010, Corporate real estate holdings and the cross-section of stock returns, The Review of Financial Studies 23, 2268-2302.

Valta, Philip, 2016, Strategic default, debt structure, and stock returns, Journal of Financial and Quantitative Analysis 51, 197-229.

Welch, Ivo, and Amit Goyal, 2008, A comprehensive look at the empirical performance of equity premium prediction, The Review of Financial Studies 21, 1455-1508.

Whited, Toni M, and Guojun Wu, 2006, Financial constraints risk, The Review of Financial Studies 19, 531-559. 
Xing, Yuhang, 2008, Interpreting the value effect through the q-theory: An empirical investigation, The Review of Financial Studies 21, 1767-1795.

Yang, Hanlin, 2019, A weighted least squares estimator of factor momentum, Technical report.

Zaremba, Adam, and Jacob Shemer, 2018, Is there momentum in factor premia? Evidence from international equity markets, Research in International Business and Finance 46, $120-130$. 


\section{A Appendix}

Table A.1: Summary of Factors

\begin{tabular}{|c|c|c|}
\hline Factor & Mnemonic & Major Reference \\
\hline \multicolumn{3}{|c|}{ US factors (public) } \\
\hline Market & MKT & Sharpe (1964) \\
\hline Size & $\mathrm{SMB}$ & Banz (1981) \\
\hline Value & HML & Fama and French $(1992,1993)$ \\
\hline Operating profitability & RMW & Fama and French (2015) \\
\hline Investment & CMA & Cooper et al. (2008); Fama and French (2015) \\
\hline Return on equity & ROE & Hou et al. (2015) \\
\hline Investment/assets & IA & Cooper et al. (2008); Hou et al. (2015) \\
\hline Management & MGMT & Stambaugh and Yuan (2017) \\
\hline Long-term reversal & REV & De Bondt and Thaler (1985) \\
\hline AQR's value & HMLD & Asness and Frazzini (2013); Asness et al. (2013) \\
\hline Betting against beta & $\mathrm{BAB}$ & Frazzini and Pedersen (2014) \\
\hline Quality & QMJ & Asness et al. (2019) \\
\hline Earning/price & $\mathrm{EP}$ & Basu (1977) \\
\hline Cashflow/price & $\mathrm{CP}$ & Lakonishok et al. (1994) \\
\hline Dividend yield & DY & Litzenberger and Ramaswamy (1979) \\
\hline Liquidity & LIQ & Pástor and Stambaugh (2003) \\
\hline Earning drift & PEAD & Chan et al. (1996) \\
\hline Financing & FIN & Daniel et al. (2019) \\
\hline Intermediary capital & ICR & He et al. (2017) \\
\hline \multicolumn{3}{|c|}{ Global factors (public) } \\
\hline Market & GMKT & Sharpe (1964) \\
\hline Size & GSMB & Banz (1981) \\
\hline Value & GHML & Fama and French $(1992,1993)$ \\
\hline Operating profitability & GRMW & Fama and French (2015) \\
\hline Investment & GCMA & Cooper et al. (2008); Fama and French (2015) \\
\hline AQR's value & GHMLD & Asness and Frazzini (2013); Asness et al. (2013) \\
\hline Betting against beta & GBAB & Frazzini and Pedersen (2014) \\
\hline Quality & GQMJ & Asness et al. (2019) \\
\hline \multicolumn{3}{|c|}{ US factors (constructed) } \\
\hline CAPM alpha & Alpha & Jensen (1968) \\
\hline CAPM beta & Beta & Black et al. (1972) \\
\hline CAPM beta squared & Beta2 & Fama and MacBeth (1973) \\
\hline Coskewness $5 \mathrm{Y}$ & CSK & Harvey and Siddique (2000) \\
\hline Coskewness 1Y (daily) & CSKD & Harvey and Siddique (2000) \\
\hline Share price & Price & Blume and Husic (1973) \\
\hline Age & Age & Barry and Brown (1984) \\
\hline Volume trend & VT & Haugen et al. (1996) \\
\hline Share turnover & STO & Datar et al. (1998) \\
\hline Volume coef.var & CVV & Chordia et al. (2001) \\
\hline Turnover coef.var & CVT & Chordia et al. (2001) \\
\hline
\end{tabular}




\begin{tabular}{|c|c|c|}
\hline CVV 6M (daily) & CVVD & Chordia et al. (2001) \\
\hline CVT 6M (daily) & CVTD & Chordia et al. (2001) \\
\hline Seasonality $1 Y$ & SE1 & Heston and Sadka (2008) \\
\hline Seasonality $2-5 Y$ & SE25 & Heston and Sadka (2008) \\
\hline Seasonality 6 - 10Y & SE610 & Heston and Sadka (2008) \\
\hline Composite equity issuance & CEI & Daniel and Titman (2006) \\
\hline Net stock issuance & NSI & Fama and French (2008) \\
\hline Share issuance $1 \mathrm{Y}$ & SI1 & Pontiff and Woodgate (2008) \\
\hline Share issuance $5 \mathrm{Y}$ & SI5 & Pontiff and Woodgate (2008) \\
\hline Bid-ask spread & BAS & Amihud and Mendelson (1989) \\
\hline Illiquidity & Illiq & Amihud (2002) \\
\hline 52-week high & W52 & George and Hwang (2004) \\
\hline Return delay & Delay & Hou and Moskowitz (2005) \\
\hline Zero-volume days $1 \mathrm{M}$ & Zero1 & Liu (2006) \\
\hline Zero-volume days $6 \mathrm{M}$ & Zero6 & Liu $(2006)$ \\
\hline Downside risk & Down & Ang et al. (2006a) \\
\hline Max daily return & Max & Bali et al. (2011) \\
\hline Total vol 1M (daily) & TV1 & Ang et al. (2006b) \\
\hline Total vol 6M (daily) & TV6 & Ang et al. (2006b) \\
\hline CAPM vol 1M (daily) & IV1 & Ang et al. (2006b) \\
\hline CAPM vol 6M (daily) & IV6 & Ang et al. (2006b) \\
\hline FF3 vol 1M (daily) & IVFF1 & Ang et al. (2006b) \\
\hline FF3 vol 6M (daily) & IVFF6 & Ang et al. (2006b) \\
\hline FF3 skewness 1Y (daily) & ISK & Boyer et al. (2010) \\
\hline Skewness 1M (daily) & SK1 & Amaya et al. (2015) \\
\hline Skewness 1Y (daily) & SK12 & Amaya et al. (2015) \\
\hline Kurtosis 1M (daily) & $\mathrm{KT} 1$ & Amaya et al. (2015) \\
\hline Kurtosis 1Y (daily) & KT12 & Amaya et al. (2015) \\
\hline Tail beta & $\mathrm{TB}$ & Kelly and Jiang (2014) \\
\hline Predictive tail beta & PTB & Kelly and Jiang (2014) \\
\hline Book equity/market & BEM & Rosenberg et al. (1985) \\
\hline Book value (FF3) growth & BG1 & Lockwood and Prombutr (2010) \\
\hline Book value growth & BG2 & Lockwood and Prombutr (2010) \\
\hline Ad expense/market & $\mathrm{ADM}$ & Chan et al. (2001) \\
\hline Ad growth & $\mathrm{ADG}$ & Lou (2014) \\
\hline R\&D/sales & RDS & Chan et al. (2001) \\
\hline $\mathrm{R} \& \mathrm{D} /$ market & $\mathrm{RDM}$ & Chan et al. (2001) \\
\hline R\&D/asset & $\mathrm{RDA}$ & $\mathrm{Li}(2011)$ \\
\hline $\mathrm{R} \& \mathrm{D} 5 \mathrm{Y}$ & RD5 & Li (2011) \\
\hline RDS change & RDSC & Eberhart et al. (2004) \\
\hline RDA change & $\mathrm{RDAC}$ & Eberhart et al. (2004) \\
\hline Return on invested capital & $\mathrm{ROIC}$ & Brown and Rowe (2007) \\
\hline Return on assets $\mathrm{Y}$ & $\mathrm{ROA}$ & Balakrishnan et al. (2010) \\
\hline Return on NOA & RNA & Soliman (2008) \\
\hline Profit margin & $\mathrm{PM}$ & Soliman (2008) \\
\hline PM change & $\mathrm{PMC}$ & Soliman (2008) \\
\hline Asset turnover & ATO & Soliman (2008) \\
\hline$\%$ asset turnover change & ATOC & Soliman (2008) \\
\hline Asset growth & $\mathrm{AG}$ & Cooper et al. (2008) \\
\hline Asset liquidity/sset & ALA & Gopalan et al. (2012) \\
\hline Asset liquidity/market & ALM & Gopalan et al. (2012) \\
\hline Gross profitability & GP & Novy-Marx (2013) \\
\hline GP change & GPC & Novy-Marx (2013) \\
\hline
\end{tabular}




\begin{tabular}{|c|c|c|}
\hline Profitability/book & $\mathrm{PB}$ & Ball et al. (2015) \\
\hline Profitability/market & PMKT & Ball et al. (2015) \\
\hline $\mathrm{OP} /$ asset & OPA & Ball et al. (2015) \\
\hline $\mathrm{OP} / \mathrm{book}$ & $\mathrm{OPB}$ & Ball et al. (2015) \\
\hline $\mathrm{OP} /$ market & $\mathrm{OPM}$ & Ball et al. (2015) \\
\hline $\mathrm{OP} /$ lagged asset & OPLA & Ball et al. (2016) \\
\hline Cashflow-based OPLA & CPLA & Ball et al. (2016) \\
\hline Profit-to-cost margin & PCM & Bustamante and Donangelo (2017) \\
\hline Operating cashflow to market & OCFM & Desai et al. (2004) \\
\hline Earning persistence & EPER & Francis et al. (2004) \\
\hline Earning volatility & EVOL & Francis et al. (2004) \\
\hline Earning smoothness & ES & Francis et al. (2004) \\
\hline Cash holdings change & $\mathrm{CHC}$ & Sodjahin (2013) \\
\hline Cash productivity & CPR & Chandrashekar and Rao (2006) \\
\hline Abnormal investment & $\mathrm{ACI}$ & Titman et al. (2004) \\
\hline Investment growth & IG & Anderson and Garcia-Feijóo (2006); Xing (2008) \\
\hline Investment growth $2 \mathrm{Y}$ & IG2 & Anderson and Garcia-Feijóo (2006) \\
\hline Investment/assets & IA 2 & Chen and Zhang (2010) \\
\hline Sales growth & $\mathrm{SG}$ & Lakonishok et al. (1994) \\
\hline Sales growth $5 \mathrm{Y}$ & SG5 & Lakonishok et al. (1994) \\
\hline Sales/price & $\mathrm{SP}$ & Barbee Jr et al. (1996) \\
\hline Fixed costs/sales & FCS & Freyberger et al. (2017) \\
\hline Hiring rate & $\mathrm{HR}$ & Belo et al. (2014) \\
\hline Inventory change & INVC & Thomas and Zhang (2002) \\
\hline Inventory growth & INVG & Belo and Lin (2012) \\
\hline$\%$ sales $-\%$ inventory & SID & Abarbanell and Bushee (1998) \\
\hline$\%$ gross margin - \% sales & GMSD & Abarbanell and Bushee (1998) \\
\hline$\%$ sales $-\%$ receivable & SRD & Abarbanell and Bushee (1998) \\
\hline$\%$ sales - \% SGA & $\mathrm{SSD}$ & Abarbanell and Bushee (1998) \\
\hline Labor force efficiency & LFE & Abarbanell and Bushee (1998) \\
\hline Effective tax rate & ETR & Abarbanell and Bushee (1998) \\
\hline Ind-adj. investment change & IIC & Abarbanell and Bushee (1998) \\
\hline Ind-adj book/market & IBM & Asness et al. (2000) \\
\hline Ind-adj size & IS & Asness et al. (2000) \\
\hline Ind-adj hiring rate & IHR & Asness et al. (2000) \\
\hline Ind-adj cashflow/price & $\mathrm{ICP}$ & Asness et al. (2000) \\
\hline SG\&A to sales & SS & Freyberger et al. (2017) \\
\hline Current ratio & $\mathrm{CR}$ & Ou and Penman (1989) \\
\hline Quick ratio & $\mathrm{QR}$ & Ou and Penman (1989) \\
\hline Sales/cash & $\mathrm{SC}$ & Ou and Penman (1989) \\
\hline Sales/intentory & SI & Ou and Penman (1989) \\
\hline Sales/receivable & $\mathrm{SR}$ & Ou and Penman (1989) \\
\hline Inventory/asset & IVA & Ou and Penman (1989) \\
\hline Depreciation/PP\&E & $\mathrm{DPP}$ & $\mathrm{Ou}$ and Penman (1989) \\
\hline$\%$ current ratio change & $\mathrm{CRC}$ & Ou and Penman (1989) \\
\hline$\%$ quick ratio change & $\mathrm{QRC}$ & Ou and Penman (1989) \\
\hline$\%$ sales / cash change & $\mathrm{SCC}$ & Ou and Penman (1989) \\
\hline$\%$ sales/inventory change & $\mathrm{SIC}$ & Ou and Penman (1989) \\
\hline$\%$ sales $/$ receivable change & $\mathrm{SRC}$ & Ou and Penman (1989) \\
\hline$\%$ inventory/asset change & IVAC & Ou and Penman (1989) \\
\hline$\%$ PP\&E change & $\mathrm{DPPC}$ & Ou and Penman (1989) \\
\hline$\%$ ROA change & $\mathrm{ROAC}$ & Ou and Penman (1989) \\
\hline$\%$ depreciation change & $\mathrm{DPC}$ & Ou and Penman (1989) \\
\hline
\end{tabular}




\begin{tabular}{|c|c|c|}
\hline Cashflow/debt & CFD & Ou and Penman (1989) \\
\hline Order backlog & $\mathrm{OB}$ & Rajgopal et al. (2003) \\
\hline Tangibility & TAN & Almeida and Campello (2007) \\
\hline Real estate ratio & RER & Tuzel (2010) \\
\hline Book leverage & $\mathrm{BL}$ & Fama and French (1992) \\
\hline Taxable/book income & TBI & Lev and Nissim (2004) \\
\hline Deferred tax change & DTC & Chaney and Jeter (1994) \\
\hline Operating leverage & $\mathrm{OL}$ & Novy-Marx (2011) \\
\hline Secured debt ratio & SDD & Valta $(2016)$ \\
\hline Covertible debt ratio & CDD & Valta (2016) \\
\hline Capital turnover & $\mathrm{CTO}$ & Haugen et al. (1996) \\
\hline Capital intensity & $\mathrm{CI}$ & Gorodnichenko and Weber (2016) \\
\hline Change in book equity & $\mathrm{CBE}$ & Richardson et al. (2005) \\
\hline Short-term investment & STI & Richardson et al. (2005) \\
\hline Long-term investment & LTI & Richardson et al. (2005) \\
\hline Financial asset & FINA & Richardson et al. (2005) \\
\hline Financial liability & FINL & Richardson et al. (2005) \\
\hline Net financial asset & NFIN & Richardson et al. (2005) \\
\hline Current operating asset & $\mathrm{COA}$ & Richardson et al. (2005) \\
\hline Current operating liability & $\mathrm{COL}$ & Richardson et al. (2005) \\
\hline Working capital & $\mathrm{WC}$ & Richardson et al. (2005) \\
\hline Noncurrent asset & $\mathrm{NCA}$ & Richardson et al. (2005) \\
\hline Noncurrent liability & NCL & Richardson et al. (2005) \\
\hline Net noncurrent asset & $\mathrm{NCO}$ & Richardson et al. (2005) \\
\hline Net operating asset & NOA & Richardson et al. (2005) \\
\hline Accrual & $\mathrm{AC}$ & Richardson et al. (2005) \\
\hline Operating accruals & $\mathrm{OAC}$ & Sloan (1996) \\
\hline$\%$ accrual & $\mathrm{PAC}$ & Hafzalla et al. (2011) \\
\hline$\%$ operating accrual & POAC & Hafzalla et al. (2011) \\
\hline Operating liability leverage & OLL & Nissim and Penman (2001) \\
\hline Long-term NOA change & LNOA & Fairfield et al. (2003) \\
\hline Scaled NOA & SNOA & Hirshleifer et al. (2004) \\
\hline Scaled NOA change & SNOAC & Hirshleifer et al. (2004) \\
\hline Asset/market & $\mathrm{AM}$ & Bhandari (1988) \\
\hline Debt/market & DM & Bhandari (1988) \\
\hline Debt/equity & DER & Bhandari (1988) \\
\hline Enterprise multiple & EM & Loughran and Wellman (2011) \\
\hline Enterprise book/price & EBP & Penman et al. (2007) \\
\hline Net debt/price & NDP & Penman et al. (2007) \\
\hline Contributed capital/market & $\mathrm{CCM}$ & Ball et al. (2019) \\
\hline Retained earnings/market & REM & Ball et al. (2019) \\
\hline Net equity financing & $\mathrm{NEF}$ & Bradshaw et al. (2006) \\
\hline Net debt financing & $\mathrm{NDF}$ & Bradshaw et al. (2006) \\
\hline Net external financing & NXF & Bradshaw et al. (2006) \\
\hline PPE and invt-to-asset change & PIA & Lyandres et al. (2008) \\
\hline Composite debt issuance & CDI & Lyandres et al. (2008) \\
\hline Payout yield & PY & Boudoukh et al. (2007) \\
\hline Net payout yield & NPY & Boudoukh et al. (2007) \\
\hline Tobin's Q & $\mathrm{Q}$ & Kaldor (1966) \\
\hline Ohlson's O-score & $\mathrm{O}$ & Dichev (1998) \\
\hline Altman's Z-score & $\mathrm{Z}$ & Dichev (1998) \\
\hline Piotroski's F-score & $\mathrm{F}$ & Piotroski et al. (2000) \\
\hline Kaplan-Zingales index & $\mathrm{KZ}$ & Lamont et al. (2001) \\
\hline
\end{tabular}




\begin{tabular}{lll} 
Whited-Wu index Y & WW & Whited and Wu (2006) \\
Herfindahl index (asset) & HA & Hou and Robinson (2006) \\
Herfindahl index (equity) & HE & Hou and Robinson (2006) \\
Herfindahl index (sales) & HS & Hou and Robinson (2006) \\
No. earning increases Q & NEI & Barth et al. (1999) \\
Revenue surprise Q & RS & Jegadeesh and Livnat (2006) \\
Tax expense surprise Q & TES & Thomas and Zhang (2011) \\
Cashflow/book volatility Q & CBV & Huang (2009) \\
Cashflow/sales volatility Q & CSV & Huang (2009) \\
Accrual volatility Q & ACV & Bandyopadhyay et al. (2010) \\
Absolute accrual Q & AAC & Bandyopadhyay et al. (2010) \\
ROA Q & ROAQ & Balakrishnan et al. (2010) \\
Cash/asset Q & CA & Palazzo (2012) \\
\hline
\end{tabular}

Table A.1: This table summarizes all factors used in this paper, including publicly available US and global factors and constructed US factors. Global factors are constructed for developed markets excluding US. The largest sample period extends from July 1965 to December 2018. 
Table A.2: Factor Portfolio Returns Relative to Fama-French Factors

\begin{tabular}{|c|c|c|c|c|c|c|c|c|}
\hline \multirow[b]{2}{*}{ Group } & \multicolumn{4}{|c|}{ Panel A: FT sorted by $\beta_{\text {seq }}$} & \multicolumn{4}{|c|}{ Panel D: FT sorted by $\left|\mu_{\text {seq }}\right|$} \\
\hline & Mean & Alpha & $t$-stat & $R_{\mathrm{adj}}^{2}$ & Mean & Alpha & $t$-stat & $R_{\text {adj }}^{2}$ \\
\hline High & 0.54 & 0.21 & 0.31 & 46.75 & -0.22 & -0.07 & -0.13 & 49.37 \\
\hline 4 & -0.08 & -0.83 & -1.43 & 57.56 & -0.80 & -0.67 & -1.24 & 58.56 \\
\hline 3 & -0.14 & -0.52 & -0.89 & 57.62 & -0.78 & -1.37 & -3.13 & 55.53 \\
\hline 2 & -0.51 & -1.29 & -2.26 & 49.48 & 0.12 & -0.68 & -1.67 & 48.60 \\
\hline \multirow[t]{2}{*}{ Low } & -0.65 & -1.13 & -3.32 & 39.28 & 0.63 & -0.79 & -1.50 & 46.68 \\
\hline & \multicolumn{4}{|c|}{ Panel B: BH sorted by $\beta_{\text {seq }}$} & \multicolumn{4}{|c|}{ Panel E: BH sorted by $\left|\mu_{\text {seq }}\right|$} \\
\hline Group & Mean & Alpha & $t$-stat & $R_{\text {adj }}^{2}$ & Mean & Alpha & $t$-stat & $R_{\text {adj }}^{2}$ \\
\hline High & 2.16 & 1.24 & 3.36 & 33.40 & 3.67 & 1.01 & 2.05 & 53.89 \\
\hline 4 & 2.06 & 1.28 & 3.97 & 53.80 & 2.80 & 0.62 & 1.68 & 69.28 \\
\hline 3 & 1.60 & 0.29 & 0.71 & 62.99 & 1.76 & 1.01 & 3.32 & 44.80 \\
\hline 2 & 2.04 & 0.32 & 1.09 & 59.57 & 1.00 & 0.51 & 2.32 & 30.79 \\
\hline \multirow[t]{2}{*}{ Low } & 1.86 & 0.72 & 2.72 & 39.99 & 0.36 & 0.39 & 1.83 & 1.08 \\
\hline & \multicolumn{4}{|c|}{ Panel C: FM sorted by $\beta_{\text {seq }}$} & \multicolumn{4}{|c|}{ Panel F: FM sorted by $\left|\mu_{\text {seq }}\right|$} \\
\hline Group & Mean & Alpha & $t$-stat & $R_{\text {adj }}^{2}$ & Mean & Alpha & $t$-stat & $R_{\text {adj }}^{2}$ \\
\hline High & 2.70 & 1.45 & 2.28 & 50.97 & 3.46 & 0.94 & 1.69 & 58.06 \\
\hline 4 & 1.98 & 0.44 & 0.86 & 60.48 & 2.00 & -0.05 & -0.09 & 55.67 \\
\hline 3 & 1.46 & -0.23 & -0.38 & 53.57 & 0.98 & -0.36 & -0.94 & 58.74 \\
\hline 2 & 1.53 & -0.97 & -1.87 & 56.45 & 1.12 & -0.17 & -0.42 & 56.23 \\
\hline Low & 1.22 & -0.41 & -1.13 & 52.09 & 0.99 & -0.40 & -0.83 & 53.56 \\
\hline
\end{tabular}

This table displays the summary statistics of the return of each factor portfolio. The portfolio is contructed within each quintile group of factors sorted by $\beta_{\text {seq }}$ and $\left|\mu_{\text {seq }}\right|$. The regression alpha of each portfolio, its robust $t$-statistic relative to the stock momentum factor and Fama and French (2015) five factors, and the percentage adjusted $R^{2}$-value are reported. The average portfolio return (mean) and alpha are annualized and reported in percentage. 

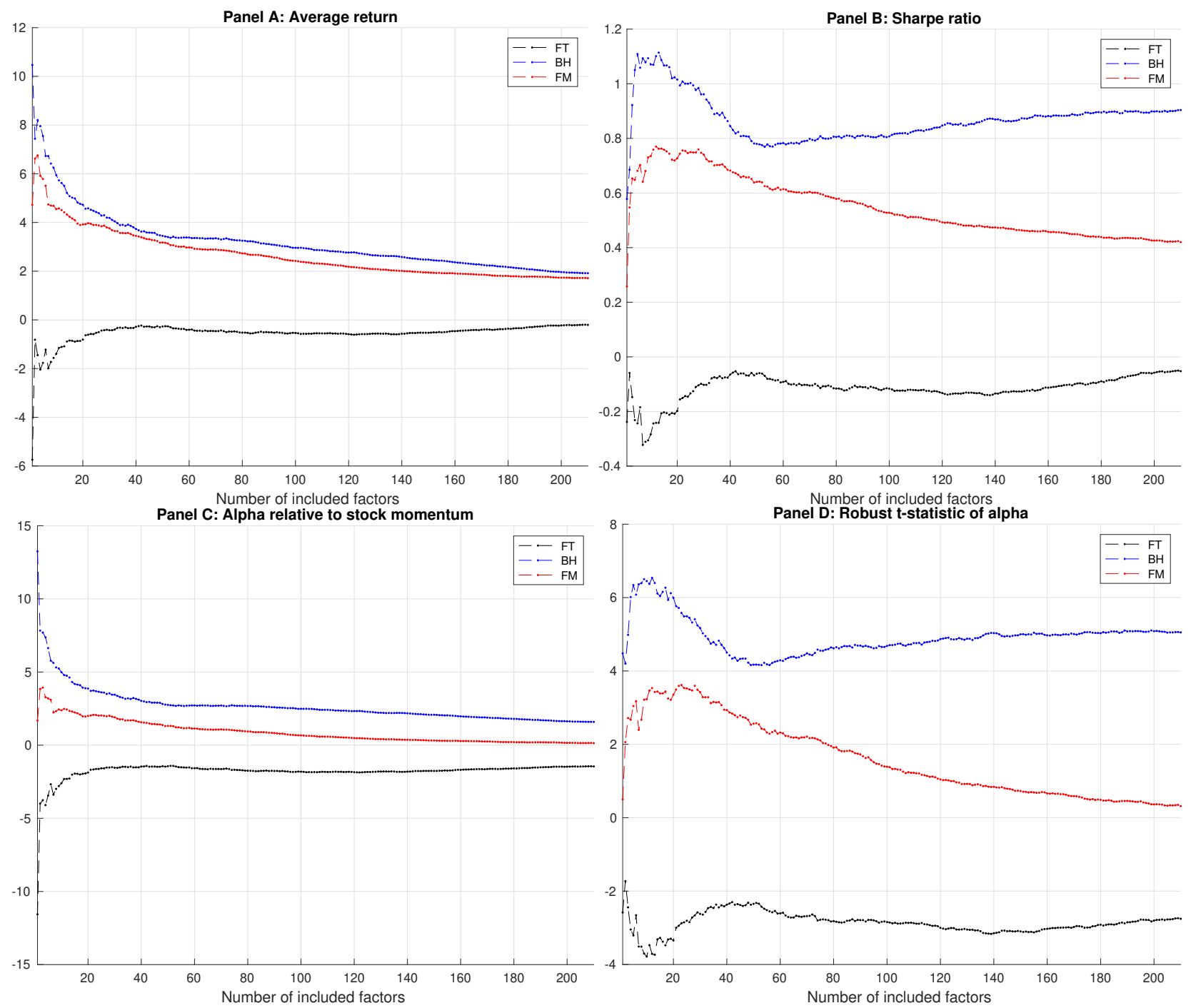

Figure 6: Sensitivity to the number of factors. This figure displays the summary statistics of factor portfolio returns when the number of included factors varies. Each month, top $n$ factors ranked by $\left|\mu_{\text {seq }}\right|$ are used to form each factor portfolio, with $n=1, \ldots, 210$. The average return and excess return relative to stock momentum (alpha) are annualized and reported in percentage. The Sharpe ratio is annualized. 

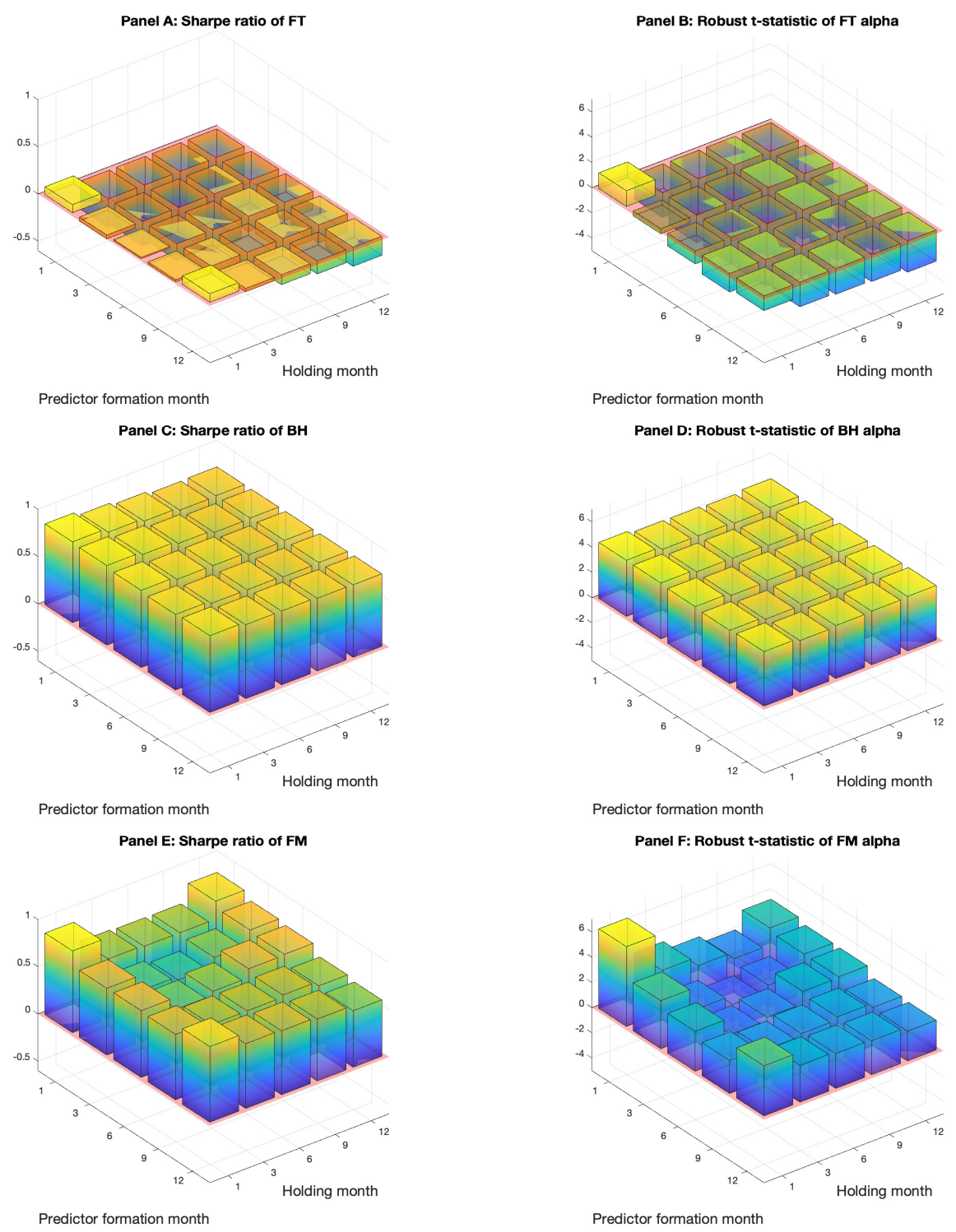

Figure 7: Different formation and holding periods. This figure displays the Sharpe ratio and robust $t$-statistic of portfolio excess returns relative to stock momentum returns. The factor timing portfolio and factor momentum portfolio are constructed based on the average return in the prior $k$ months and held for $h$ months with $k=h=1,3,6,9,12$. Portfolio formation follows Jegadeesh and Titman (1993) to obtain nonoverlapping monthly returns. Each factor portfolio is formed on the top quintile of factors sequentially sorted by $\left|\mu_{\text {seq }}\right|$. The portfolio excess return is the estimate of the intercept from regressing portfolio returns on stock momentum returns. The Sharpe ratio is annualized. 

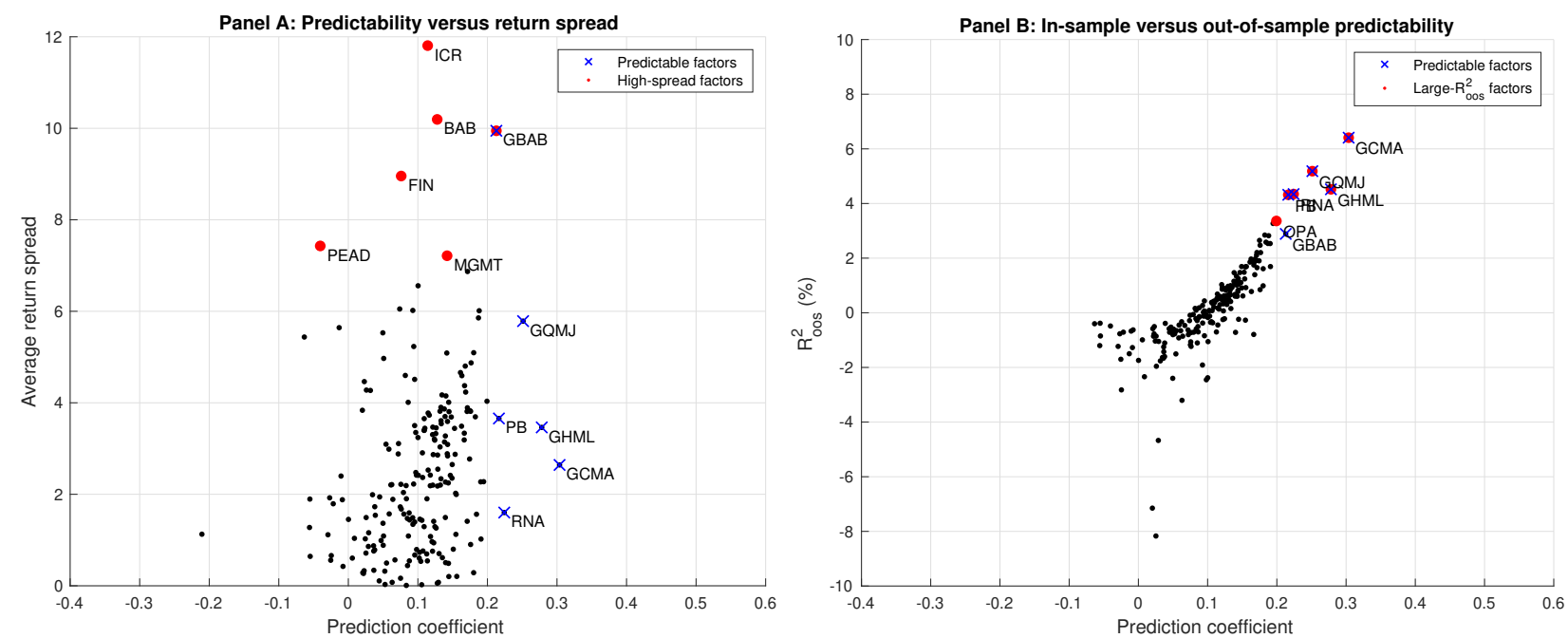

Figure 8: Bivariate scatter plot of factor return characteristics. This figure displays the bivariate scatter plot of (1) the OLS estimate of $\beta$ in equation (6) versus the absolute average return spread, and (2) the OLS estimate of $\beta$ versus the $R_{\text {oos }}^{2}$-value in percentage. In estimating $\beta$, the prior one-month return is used to predict return in the next month. The return spread is annualized and reported in percentage. 

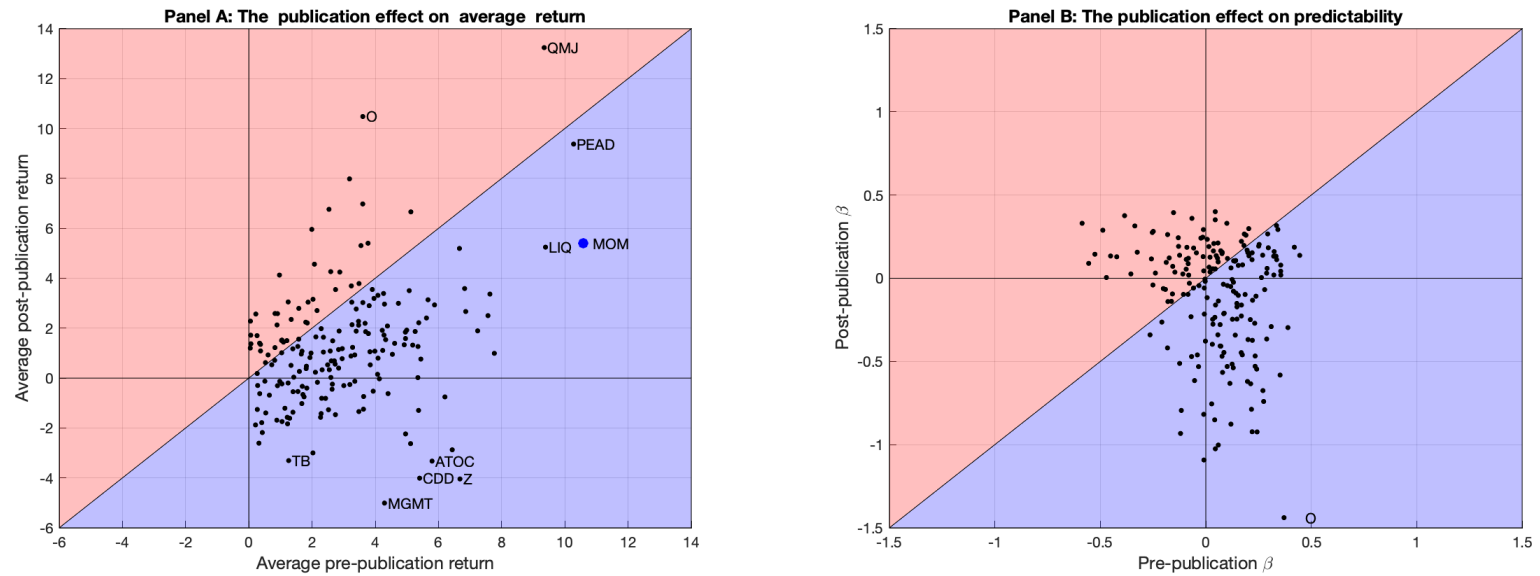

Figure 9: The publication effect on factor returns. This figure compares the estimates of factor return characteristics pre- and post-publication. Specifically, Panel A compares the average pre- and post-publication return. Factors are rotated to have a positive pre-publication return. The average return of factors in the blue (red) area weakens (strengthens) postpublication. The average return is annualized and reported in percentage. Panel B compares the estimated prediction coefficient in equation (6) pre- and post-publication. Factors in the blue (red) area become less (more) persistent with a smaller (larger) prediction coefficient post-publication. To be included in both figures, factors are required to have a minimum of 36 monthly observations both pre- and post-publication. This filter rules out 20 factors, leaving 190 factors for display. 

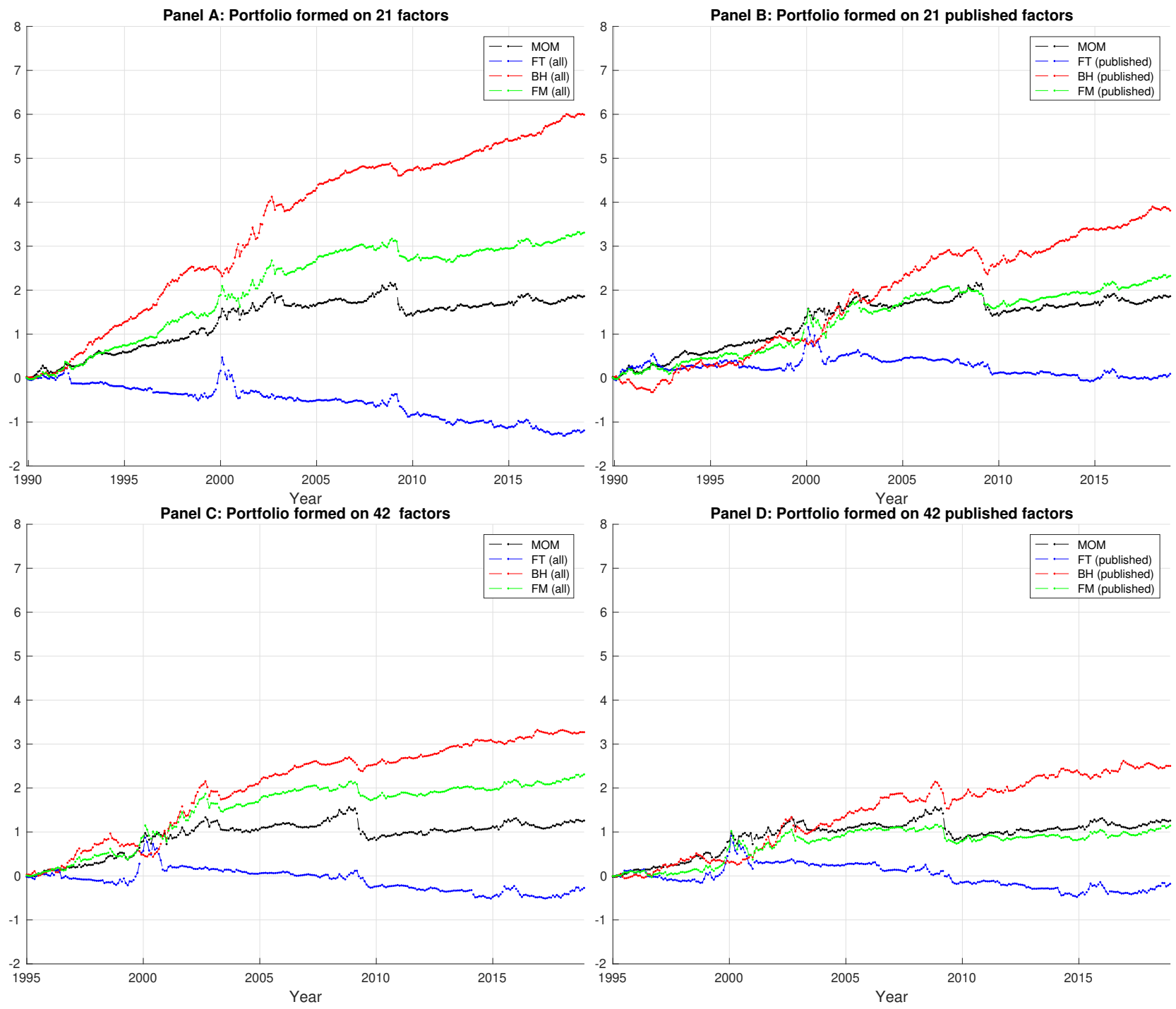

Figure 10: Cumulative return of factor portfolios. This figure displays the cumulative sum of the return of the stock momentum factor and each factor portfolio. MOM is the stock momentum factor. Factor portfolios are formed on the top 21 or 42 factors sequentially sorted by $\left|\mu_{\text {seq }}\right|$. Each factor portfolio is levered to have the same standard deviation as the stock momentum factor. The sample period extends from December 1989 (January 1995) to December 2018, where there are a minimum of 21 (42) published factors. 

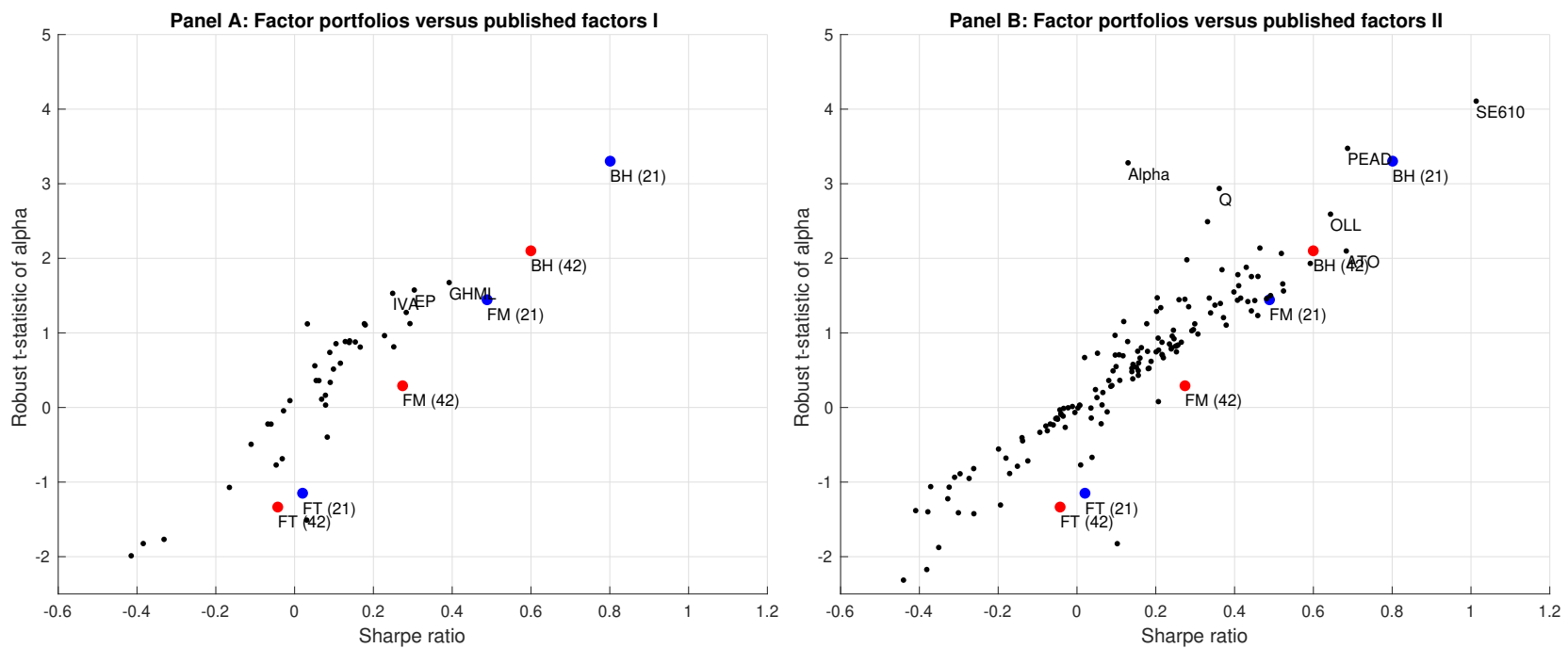

Figure 11: Bivariate scatter plot of factor portfolios and published factors. This figure displays the bivariate scatter plot of the Sharpe ratio and robust $t$-stastistic of the regression alpha relative to stock momentum. Panel A displays the estimates for factors published before January 1995 with the sample period extending from January 1995 to December 2018. Panel B displays the estimates for all factors. The estimates are obtained using all post-publication data, with a minimum of 120 monthly returns required for each factor. The factor timing portfolio, buy-and-hold portfolio and factor momentum portfolio formed on the top 21 and 42 factors ranked by the return spread $\left(\left|\mu_{\text {seq }}\right|\right)$ are also displayed. 
Table A.3: Factor Portfolio Returns Relative to HXZ Factors

\begin{tabular}{|c|c|c|c|c|c|c|c|c|}
\hline \multirow[b]{2}{*}{ Group } & \multicolumn{4}{|c|}{ Panel A: FT sorted by $\beta_{\text {seq }}$} & \multicolumn{4}{|c|}{ Panel D: FT sorted by $\left|\mu_{\text {seq }}\right|$} \\
\hline & Mean & Alpha & $t$-stat & $R_{\text {adj }}^{2}$ & Mean & Alpha & $t$-stat & $R_{\text {adj }}^{2}$ \\
\hline High & 0.54 & 0.27 & 0.38 & 42.03 & -0.22 & -0.00 & -0.01 & 42.73 \\
\hline 4 & -0.08 & -0.72 & -1.24 & 56.42 & -0.80 & -0.25 & -0.38 & 56.37 \\
\hline 3 & -0.14 & -0.16 & -0.25 & 56.29 & -0.78 & -1.05 & -2.52 & 55.83 \\
\hline 2 & -0.51 & -0.94 & -1.63 & 50.93 & 0.12 & -0.48 & -1.15 & 49.89 \\
\hline \multirow[t]{2}{*}{ Low } & -0.65 & -0.74 & -2.18 & 42.48 & 0.63 & -0.57 & -1.05 & 48.24 \\
\hline & \multicolumn{4}{|c|}{ Panel B: BH sorted by $\beta_{\text {seq }}$} & \multicolumn{4}{|c|}{ Panel E: BH sorted by $\left|\mu_{\text {seq }}\right|$} \\
\hline Group & Mean & Alpha & $t$-stat & $R_{\text {adj }}^{2}$ & Mean & Alpha & $t$-stat & $R_{\text {adj }}^{2}$ \\
\hline High & 2.16 & 1.38 & 3.49 & 21.06 & 3.67 & 1.46 & 2.29 & 30.35 \\
\hline 4 & 2.06 & 1.46 & 4.23 & 43.17 & 2.80 & 0.67 & 1.49 & 57.08 \\
\hline 3 & 1.60 & 0.40 & 0.88 & 49.35 & 1.76 & 1.07 & 3.41 & 38.55 \\
\hline 2 & 2.04 & 0.43 & 1.20 & 51.12 & 1.00 & 0.57 & 2.46 & 28.12 \\
\hline \multirow[t]{2}{*}{ Low } & 1.86 & 0.53 & 2.00 & 41.29 & 0.36 & 0.44 & 1.90 & 1.03 \\
\hline & \multicolumn{4}{|c|}{ Panel C: FM sorted by $\beta_{\text {seq }}$} & \multicolumn{4}{|c|}{ Panel F: FM sorted by $\left|\mu_{\text {seq }}\right|$} \\
\hline Group & Mean & Alpha & $t$-stat & $R_{\mathrm{adj}}^{2}$ & Mean & Alpha & $t$-stat & $R_{\text {adj }}^{2}$ \\
\hline High & 2.70 & 1.65 & 2.57 & 51.21 & 3.46 & 1.46 & 2.62 & 55.06 \\
\hline 4 & 1.98 & 0.74 & 1.44 & 61.12 & 2.00 & 0.42 & 0.77 & 56.87 \\
\hline 3 & 1.46 & 0.24 & 0.39 & 55.78 & 0.98 & 0.02 & 0.05 & 60.97 \\
\hline 2 & 1.53 & -0.51 & -1.00 & 56.49 & 1.12 & 0.08 & 0.20 & 58.10 \\
\hline Low & 1.22 & -0.21 & -0.62 & 52.61 & 0.99 & -0.14 & -0.28 & 55.51 \\
\hline
\end{tabular}

This table displays the summary statistics of the return of each factor portfolio. The portfolio is contructed within each quintile group of factors sorted by $\beta_{\text {seq }}$ and $\left|\mu_{\text {seq }}\right|$. The regression alpha of each portfolio, its robust $t$-statistic relative to the stock momentum factor and Hou et al. (2015) factors, and the percentage adjusted $R^{2}$-value are reported. The average portfolio return (mean) and alpha are annualized and reported in percentage. 